\title{
Direitos de Propriedade Industrial e Acesso a Medicamentos para o Tratamento da Aids no Brasil
}

\author{
INTELLECTUAL PROPERTY RIGHTS AND ACCESS TO DRUGS \\ FOR AIDS TREATMENT IN BRAZIL
}

Amélie Robine ${ }^{(*)}$

\section{RESUMO}

O Acordo TRIPS, que entrou em vigor em $1^{\circ}$ de janeiro de 1995 , obriga os Estados-membros da OMC a reconhecerem a patente de produtos e processos farmacêuticos, proibindo assim que sejam copiados, uma prática comum em certos países que adotam políticas de distribuição de medicamentos gratuita ou a preços baixos. O acordo prevê flexibilizações favoráveis à proteção da saúde pública, tais como licenciamento compulsório ou importações paralelas. Diante das exigências sanitárias impostas pela pandemia de AIDS, a decisão de 30 de agosto de 2003 da OMC introduziu novas flexibilizações, a fim de de resolver os problemas de acesso aos medicamentos dos países mais pobres. O Brasil, que desenvolve um programa, reconhecido mundialmente, de acesso universal e gratuito aos medicamentos para o tratamento da AIDS, aceitou as normas internacionais relativas à patente de medicamentos em 1997, data em que entrou em vigor sua lei de propriedade industrial. Assim, o país teve que conciliar as exigências sanitárias e o sistema de patentes de medicamentos. Ao analisar a lei brasileira de propriedade industrial, constata-se que adotou-se estratégias paradoxais. Se de um lado, o país busca utilizar plenamente as possibilidades de flexibilizações tradicionais, permitidas pelo direito de patentes, com o objetivo de limitar o impacto das patentes farmacêuticas, por outro, desperdiça as possibilidades de flexibilização do Acordo TRIPS.

\section{Palavras-chave}

Acesso a Medicamentos; Acordo TRIPS; AIDS; Brasil; Direito de Propriedade Intelectual.

$\left(^{\star}\right)$ Doutoranda em Direito na Universidade Paris I - Panthéon-Sorbonne. Recebido em 31.1.7. Aprovado em 25.4.7. 


\title{
ABSTRACT
}

Come into effect on January 1st 1995 , the TRIPS Agreement obliges the WTO Members to recognize the patentability of pharmaceutical products and processes. It forbids the copies made by countries which adopts politics of free distribution of drugs or with low prices. The Agreement has included some flexibilities to protect public health, such as compulsory licenses and parallel imports. Answering sanitary requirements imposed by the AIDS pandemic, the decision of August 30 $\frac{\text { th }}{2}, 2003$, introduced new flexibilities to solve the problem related to drug access of the poorest countries. Brazil, which has developed a worldwide recognized program of universal and free access to HIV/AIDS medicines, complied with the international obligations relative to patentability of medicines in 1997, when its industrial property law has been introduced. The country has to conceal sanitary requirements and drug patentability. The analysis of Brazilian's industrial property law shows that the country has adopted paradoxal strategies. Indeed, Brazil has tried to utilize the traditional flexibilities offered by the patents right, limiting the impact of the pharmaceutical patents, but it has not utilized the range of flexibilities of the TRIPS Agreement.

\section{Key words}

\author{
Drug Access; Brazil; HIV/AIDS; Industrial Property Rights; TRIPS \\ Agreement.
}

\section{INTRODUÇÃO}

Em nível internacional, os direitos de propriedade industrial, e portanto, o direito de patentes, são regidos pelo Acordo TRIPS (Acordo sobre Aspectos dos Direitos de Propriedade Intelectual Relacionados com o Comércio) ${ }^{(1)}$ que entrou em vigor em $1^{\circ}$. de janeiro de 1995. O acordo impõe aos Estados-membros da Organização Mundial do Comércio (OMC) obrigações mínimas, em diferentes áreas da propriedade intelectual. Especificamente com relação ao direito de patente, o documento obriga as nações a reconhecerem o patenteamento de produtos e processos farmacêuticos ${ }^{(2)}$. Esta exigência é justificada pela idéia de que as patentes da área farmacêutica são

(1) O acordo depende da arquitetura geral da Organização Mundial do Comércio e pode ser consultado no site:WORLD TRADE ORGANIZATION. Disponivel <http://www.wto.org/french/docs_f/ legal_f/27-trips.pdf>.

(2) $\bigcirc$ art. 27 do documento dispõe que "uma patente poderá ser obtida por toda invenção, de produto ou processo, em todas as áreas tecnológicas, com a condição de que seja uma novidade e implique em uma atividade inventiva e que seja suscetível de aplicação industrial". 
necessárias para estimular a pesquisa e o desenvolvimento de novos medicamentos. Por meio da concessão de um monopólio de 20 anos $^{(3)}$ para a exploração do produto e/ou processos, dado aos titulares da patente, pretende-se garantir um retorno dos investimentos realizados para a pesquisa de novas moléculas. As patentes farmacêuticas - à luz dos monopólios constituem uma exceção ao princípio da livre concorrência e, em geral, elevam os preços dos medicamentos ${ }^{(4)}$.

Bem, se nos países desenvolvidos, os custos de medicamentos patenteados são de responsabilidade do sistema de seguridade social, nas nações em desenvolvimento, ficam a cargo dos doentes, o que levanta a questão do acesso, pelas populações mais pobres, aos medicamentos. Para remediar esse problema, os países em desenvolvimento adotam, tradicionalmente, legislações que excluem medicamentos do processo de patente. Estas leis permitem que as nações mais avançadas, entre as em desenvolvimento, fabriquem localmente cópias mais baratas das drogas patenteadas.

Com o objetivo de salvaguardar a concorrência, de um lado, e a saúde pública, de outro, o Acordo TRIPS incluiu flexibilidades "clássicas" relativas ao exercício do direito de patente: licenças compulsórias ${ }^{(5)}$, importações paralelas $^{(6)}$, ou ainda, a faculdade de um Estado-membro de tomar as medidas necessárias para proteger a saúde pública, desde que elas não se constituam em um obstáculo ao comércio(7). Estas flexibilizações foram, de toda forma, consideradas muito tímidas, sob o ponto de vista das exigências sanitárias e, mais particularmente, dentro de um contexto de pandemia da AIDS, que afeta drasticamente os países pobres. Por esta razão, a fim de resolver os problemas de saúde pública das nações menos desenvolvidas, as negociações da Rodada Doha, no âmbito da OMC, resultaram em uma decisão, editada em 30 de agosto de 2003, que buscou solucionar a questão do acesso aos medicamentos entre os países mais pobres, independentemente das soluções "clássicas", introduzindo novas possibilidades de flexibilizações.

O Brasil faz parte dos países emergentes ${ }^{(8)}$, caracterizado por grandes desigualdades econômicas e sociais. A nação também é exemplo mundial,

(3) Cf. Art. 33 do Acordo TRIPS.

(4) Cf. por exemplo, B. Remiche et H. Desterbecq, "Les brevets pharmaceutiques dans les accords

du GATT: l'enjeu ?", RIDE, 1996, p. 13.

(5) Art. 31 do Acordo TRIPS.

(6) Art. 6 do Acordo TRIPS.

(7) Art. 8 do Acordo TRIPS.

(8) Os países emergentes ou Novos Países Industriais (NPI) são aqueles que apresentam um ritmo de crescimento sustentado e que são, atualmente, produtores importantes de bens manufaturados. São três os critérios das organizações internacionais para definir esses países:

- forte crescimento econômico e aumento contínuo da oferta de empregos no setor industrial;

- salário médio elevado em relação aos outros países em desenvolvimento e redução das diferenças entre salários, considerando os países desenvolvidos; 
pois vem obtendo sucesso no controle da propagação da epidemia da AIDS ${ }^{(9)}$, ao contrário das previsões dos especialistas que acreditavam que o país iria se "africanizar". Essa conquista deve-se a implantação de um programa nacional de luta contra a AIDS e as doenças sexualmente transmissíveis. Este programa não impediu o país de adaptar sua legislação aos parâmetros internacionais de propriedade industrial, como os definidos pelo Acordo TRIP, se bem que, o Brasil já contava com uma indústria de cópias desenvolvida, pois sua legislação excluía os produtos farmacêuticos dos processos de patente.

Parece, assim, ser pertinente estudar como o Brasil harmonizou as exigências sanitárias com os impedimentos impostos pelo direito internacional de patentes, mais particularmente na área farmacêutica. Em qual medida a lei da propriedade industrial brasileira conseguiu articular, de um lado, as exigências do comércio mundial, e do outro, o imperativo do acesso aos medicamentos contra a AIDS? A análise mostra que, se algumas disposições são, em geral, bastante originais e conseguem articular esses interesses (I), outras, por sua vez, estão longe de satisfazerem as expectativas (II).

\section{AS DISPOSIÇÕES DA LEGISLAÇÃO BRASILEIRA EM FAVOR DO ACESSO AOS MEDICAMENTOS}

Para se colocar em conformidade com as disposições do Acordo TRIPS, - Brasil adotou uma nova legislação em matéria de propriedade industrial. Trata-se da Lei Federal n. 9.279, de 14 de maio de $1996^{(10)}$ que revela uma característica inovadora, na medida em que utiliza a técnica clássica do direito de patentes, dentro de uma ótica da saúde pública $(A)$ e que permite às instituições públicas regular a outorga de patentes farmacêuticas, de uma maneira que favoreça o acesso aos medicamentos, para as populações mais pobres (B).

\section{A. Técnicas clássicas do direito de patente para proteger a saúde pública}

A Lei Federal n. 9.279, de 1996 integrou critérios e exclusões clássicas de patenteabilidade (1), assim como introduziu um mecanismo de licença compulsória (2) dentro de uma ótica sanitária.

- orientação da economia em direção ao exterior e aumento do peso das exportações de produtos manufaturados.

Cf. Teulon, F. Problèmes économiques contemporains: les pays en développement. Les Fondamentaux, Hachette, 1999. p. 151.

(9) O Brasil contava com cerca de 593 mil pessoas contaminadas em 2004. A taxa de prevalência em 2005 foi estimada em 0,7\% (na França, esta taxa é de 0,4\%). Source: MINISTÉRIO DA SAÚDE. Disponível em: <http://www.aids.gov.br/data/Pages/LUMIS13F4BF21PTBRIE.htm>.

(10) DOU de 15 de maio de 1996. 


\section{Os critérios e exclusões clássicas de patenteabilidade}

Ainda que a Lei Federal n. 5.772, de 21 de dezembro de $1971^{(11)}$ prevesse apenas dois critérios de patenteabilidade (a novidade e a aplicação industrial), o art. $8^{\circ}$ da Lei n. 9.279(12) retoma os três critérios definidos na legislação internacional: "uma patente poderá ser obtida por toda a invenção de produto ou de processo, em todas as áreas tecnológicas, sob a condição de que este processo ou produto apresente novidade e inovação tecnológica e que seja suscetível de aplicação industrial"(13). Assim este novo texto integrou os produtos e processos farmacêuticos no campo da patenteabilidade, a partir de 14 de maio de 1997, data de entrada em vigor desta lei ${ }^{(14)}$.

Para limitar o máximo possível o domínio da patenteabilidade, o artigo da Lei n. 9.279 retoma as exclusões previstas pelo Acordo TRIPS : as descobertas, teorias científicas e métodos matemáticos, as concepções puramente abstratas, os esquemas, planos, métodos comerciais, as obras literárias, os programas de computador, regras de jogos, técnicas e métodos operatórios e cirúrgicos, assim como os métodos terapêuticos ou diagnósticos aplicados ao corpo humano ou animal, todas as partes dos seres vivos e materiais biológicos encontrados na natureza etc ${ }^{(15)}$.

Do ponto de vista da questão de acesso aos medicamentos, estas mudanças tiveram várias conseqüências. De um lado, nenhuma droga comercializada no mundo antes de 14 de maio de 1997 poderia ser patenteada no Brasil, pois a lei não tinha efeito retroativo. Assim, as moléculas de base utilizadas no tratamento da AIDS, como o AZT, Nevirapine ou o Indinavir

(11) Lei de 21 de dezembro de 1971 que instituiu um código de propriedade industrial, DOU de 31 de dezembro de 1971.

(12) Art. 8: "É patenteável a invenção que atenda aos requisitos de novidade, atividade inventiva e aplicação industrial".

(13) Art. 27 do Acordo TRIPS.

(14) De qualquer maneira, as disposições foram previstas para os pedidos de patentes depositados entre $1^{\circ}$ de janeiro de 1995 e 14 de maio de 1997 , valendo o mesmo para os pipelines. Retornaremos futuramente a estas disposições.

(15) Art. 10. "Não se considera invenção nem modelo de utilidade:

1 - descobertas, teorias científicas e métodos matemáticos;

II - concepções puramente abstratas;

III - esquemas, planos, princípios ou métodos comerciais, contábeis, financeiros, educativos, publicitários, de sorteio e de fiscalização;

IV - as obras literárias, arquitetônicas, artísticas e científicas ou qualquer criação estética;

$\mathrm{V}$ - programas de computador em si;

VI - apresentação de informações;

VII - regras de jogo;

VIII - técnicas e métodos operatórios ou cirúrgicos, bem como métodos terapêuticos ou de diagnóstico, para aplicação no corpo humano ou animal; e

IX - o todo ou parte de seres vivos naturais e materiais biológicos encontrados na natureza, ou ainda que dela isolados, inclusive o genoma ou germoplasma de qualquer ser vivo natural e os processos biológicos naturais". 
podiam ser produzidas pela indústria de genéricos brasileira legalmente. Todavia, no que se refere aos medicamentos patenteados no Brasil após esta data, eles não poderiam ser fornecidos por laboratórios brasileiros, a não ser que as multinacionais detivessem as patentes de tais drogas, dando-Ihes a outorga de uma licença voluntária - o que é muito difícil na prática - ou que o governo tenha emitido uma licença compulsória, autorizando os laboratórios nacionais a produzir os medicamentos patenteados sem o consentimento do titular da patente - o que supõe a reunião de condições e circunstâncias bem precisas (em caso de urgência sanitária, por exemplo). $\mathrm{Na}$ grande maioria dos casos, os tratamentos de última geração são aqueles oferecidos pelas multinacionais a preços mais elevados do que os genéricos, o que coloca em risco o programa brasileiro de acesso a medicamentos contra a AIDS.

Ao lado de critérios e exclusões clássicas de patenteabilidade, o Brasil integrou plenamente uma das flexibilidades previstas pelo Acordo TRIPS e a Declaração de Doha: o mecanismo do licenciamento compulsório que favorece $o$ acesso aos medicamentos.

\section{A integração do mecanismo de licenciamento compulsório}

A licença compulsória é uma flexibilização clássica do direito de patentes, em virtude da qual, dentro de certas hipóteses, um terceiro pode contar com uma licença de exploração da invenção, contrariamente à vontade do titular da patente. Verdadeira "brecha legal"(16) dentro do monopólio, a restrição de direito exclusivo tem como fundamento considerações de eqüidade: o monopólio deve se submeter ao interesse geral, restando ao titular não mais do que um direito de indenização. Autorizado pelo art. 31 do Acordo TRIPS, a maioria dos Estados organizaram um regime de exceção clássica em suas legislações. E se o Brasil não escapa a esta regra (a), de toda maneira, o país tem uma estratégia bastante original de utilizar o licenciamento compulsório (b).

\section{a. O princípio do licenciamento compulsório como um instrumento de acesso aos medicamentos}

$\mathrm{O}$ art. 31 do Acordo TRIPS deixa aos Estados-membros a liberdade de determinar os motivos para que seja conferida uma licença compulsória; porém, ele estabelece uma série de condições a serem respeitadas. Primeiro, o requerente deve, preliminarmente, obter uma licença voluntária do titular da patente da invenção (salvo em situações de urgência nacional, outras

(16) Pollaud-Dullian, F. Droit de la propriété industrielle. Paris: Montchrestien, 1999. p. 233. (Collection Domat droit privé). 
cirscunstâncias de extrema urgência ou em caso de utilização pública com fins não comerciais). Depois, a abrangência e a duração da licença devem ser limitadas. Além disso, o artigo determina que a licença não será exclusiva, inacessível e deverá ser conferida, principalmente, por uma autoridade. Por fim, a licença compulsória deve destinar-se principalmente ao abastecimento do mercado interno e o detentor do direito deverá receber uma remuneração adequada.

Na prática, a licença é conferida por uma autoridade judicial ou pública e as razões mais comuns para sua concessão são: licença por não exploração da invenção; licença de dependência (que oferece proteção nas hipóteses em que um inventor desenvolve aperfeiçoamentos sobre um invento já patenteado) ; licença em interesse da saúde pública(17), em função do interesse público, da economia nacional e da defesa nacional.

Dentro da problemática do acesso aos medicamentos, a licença compulsória revela um interesse preciso(18), uma vez que, em caso de uma pandemia de AIDS ou gripe aviária, por exemplo, ela pode ser utilizada para fabricar genéricos, passando para outros os direitos do titular da patente. $O$ interesse público prevalece diante do interesse privado. Esta flexibilidade foi reafirmada pela Declaração de Doha sobre o Acordo TRIPS e a Saúde Pública, de 14 de novembro de $2001^{(19)}$ que dispõe: "o reconhecimento da gravidade dos problemas de saúde pública que afetam vários países em desenvolvimento e as nações pobres, em particular os decorrentes da AIDS, tuberculose, paludismo e outras epidemias [...] convencionou-se que o Acordo TRIPS não pode e não deve impedir os Estados-membros de implementar medidas de proteção à saúde de suas populações. [...] Cada Estado-membro tem o direito de conceder licenciamentos compulsórios e a liberdade de determinar os motivos pelos quais as licenças foram conferidas".

A licença compulsória pode também ser utilizada como um instrumento que facilita o acesso aos medicamentos, a partir do momento em que autoriza fabricantes locais a produzir, sem a anuência do titular da patente, os medicamentos patenteados a custos geralmente inferiores e também pelo fato de que a licença permite multiplicar os estoques em caso de pandemias. Além disso, o documento pode ser utilizado como um instrumento

(17) Cf., por exemplo, o art. L.613-16 do Código Francês do Direito à Propriedade Intelectual que dispõe que, se o interesse da saúde pública exige, o Ministério da Saúde pode solicitar ao Ministério responsável pela área de Propriedade Intelectual que submeta uma patente de medicamento ou de um processo industrial farmacêutico a um regime de licença compulsória de ofício uma patente de medicamento ou de um processo industrial farmacêutico.

(18) Cf., por exemplo, os Estados Unidos que tinha ameaçado a Bayer com uma licença compulsória para o Cipro, dentro de um cenário de risco de doenças provocadas pela aspiração de fuligem decorrentes do atentado de 11 de setembro de 2001.

(19) Documento n. WT/MIN(01)/DEC/2, publicado no site da OMC: WORLD TRADE ORGANIZATION. Disponível em: <http://docsonline.wto.org/DDFDocuments/u/WT/Min01/DEC2.doc>. 
de política industrial. De fato, é considerado um meio para que um país emergente possa adquirir conhecimentos científicos e tecnológicos a fim de desenvolver uma indústria farmacêutica local.

Em virtude da Seção III, do Capítulo VII, da Lei Federal n. 9.279, no Brasil, uma licença compulsória pode ser outorgada, por abuso de direito do titular da patente, abuso do poder econômico, não exploração da invenção no território nacional, comercialização insuficiente (ou que não satisfaça às necessidades do mercado), licença de dependência ou ainda em caso de urgência nacional ou interesse público(20). Se o campo de aplicação do licenciamento compulsório parece abrangente, sua concessão é, de qualquer forma, submetida a condições restritivas: uma licença apenas pode ser solicitada por uma instituição que apresente interesse legítimo e capacidades técnicas ou econômicas indispensáveis à exploração efetiva do objeto patenteado; a licença somente pode ser solicitada após três anos do patenteamento (exceto em caso de urgência nacional, interesse público ou licença de dependência).

Note-se que o Brasil apresenta a particularidade ${ }^{(21)}$ de ter definido os conceitos de urgência nacional e de interesse público por meio do Decreto 3.201 , de 1999(22). Entende-se urgência nacional como "um perigo público iminente"(23) e interesse público como "Os fatos relacionados, dentre outros, à saúde pública, nutrição e à defesa do meio ambiente, bem como aqueles de primordial importância para o desenvolvimento tecnologico ou sócioeconômico do Pais"(24).

(20) Seção III: "Da Licença Compulsória

Art. 68. O titular ficará sujeito a ter a patente licenciada compulsoriamente se exercer os direitos dela decorrentes de forma abusiva, ou por meio dela praticar abuso de poder econômico, comprovado nos termos da lei, por decisão administrativa ou judicial.

$\S 1^{\circ}$ Ensejam, igualmente, licença compulsória:

1 - a não exploração do objeto da patente no território brasileiro por falta de fabricação ou fabricação incompleta do produto, ou, ainda, a falta de uso integral do processo patenteado, ressalvados os casos de inviabilidade econômica, quando será admitida a importação; ou

II - a comercialização que não satisfizer às necessidades do mercado [...].

Art. 70. A licença compulsória será ainda concedida quando, cumulativamente, se verificarem as seguintes hipóteses:

I - ficar caracterizada situação de dependência de uma patente em relação a outra;

II - o objeto da patente dependente constituir substancial progresso técnico em relação à patente anterior; e

III — o titular não realizar acordo com o titular da patente dependente para exploração da patente anterior [...].

Art. 71. Nos casos de emergência nacional ou interesse público, declarados em ato do Poder Executivo Federal, desde que o titular da patente ou seu licenciado não atenda a essa necessidade, poderá ser concedida, de ofício, licença compulsória, temporária e não exclusiva, para a exploração da patente, sem prejuízo dos direitos do respectivo titular."

(21) Estes conceitos não são definidos no Acordo TRIPS.

(22) Decreto n. 3.201 de 6 outubro de 1999, publicado no DOU em 7 de outubro de 1999.

(23) Art. $2^{\circ}, \S 1^{\circ}$ : "Entende-se por emergência nacional o iminente perigo público, ainda que apenas em parte do territorio nacional".

(24) Art. $2^{\circ}, \S 2^{\circ}$ : “Consideram-se de interesse público os fatos relacionados, dentre outros, à saúde publica, à nutrição, à defesa do meio ambiente, bem como aqueles de primordial importância para o desenvolvimento tecnológico ou sócioeconômico (sic) do País". 
A originalidade brasileira, entretanto, está, sobretudo, na utilização do licenciamento compulsório como instrumento de negociação dos preços de medicamentos. Mais exatamente, o país já fez várias ameaças de licenciamento compulsório, para conseguir reduções de preços significativas de patentes de medicamentos anti-retrovirais.

\section{b. Licenciamento compulsório como ameaça}

O Brasil já se utilizou da licença compulsória como uma verdadeira estratégia de negociação de preços de medicamentos de última geração para o tratamento da AIDS, protegidos pelas patentes das multinacionais. Apenas $o$ anúncio de que iria conceder o licenciamento era suficiente para que se iniciassem as negociações com as farmacêuticas multinacionais.

O país colocou em prática esta estratégia, pela primeira vez, em 2001. Tratava-se de negociar o preço de quatro anti-retrovirais de nova geração (Efavirenz, Indinavir, Nelfinavir e Lopinavir/r) com os laboratórios detentores das patentes sobre as moléculas: Merck \& Co, Roche e Abbott. Apoiando-se na capacidade da Far-Manguinhos de reproduzir, pela técnica da engenharia inversa, os medicamentos em questão a custos bastante competitivos, o governo brasileiro ameaçava as multinacionais de conceder uma licença compulsória. De fato, os preços proibitivos das moléculas limitavam o número de doenças incluídas no programa brasileiro de combate à AIDS e comprometia sua viabilidade ${ }^{(25)}$. O país obteve reduções de preços de $40 \%$ a $65 \%$ e um acordo de princípio para a transferência de tecnologia do Indinavir (licença voluntária) foi assinado entre a Merck \& Co e o laboratório FarManguinhos. Este acordo é importante porque ele mostra a sinergia entre a política de preços e a política industrial.

O último acordo foi assinado em 10 de outubro de $2005 \mathrm{com}$ a Abbott para o Kaletra (Lopinavir/r). Desta vez, o governo brasileiro foi ainda mais longe na utilização desta estratégia ${ }^{(26)}$, visto que, por meio de uma Portaria Ministerial de 24 de junho de $2005^{(27)}$, declarou de interesse público os me-

(25) Bermudez, J., Auxiliadora Oliveira M. e Chaves, G. Costa. O acordo TRIPS da OMC e os desafios para a saúde pública. In: Acceso a medicamentos: derecho fundamental. Papel del Estado. Rio de Janeiro: Fiocruz/ENSP, 2004. p. 76.

(26) NOTA DO EDITOR: No caso do anti-retroviral Efavirenz, em novembro de 2006, o Brasil iniciou negociações com o laboratório detentor da patente do medicamento, Merck Shape \& Dohme Co, nas quais pedia a redução de preços da droga para os mesmos valores praticados no mercado tailandês. O insucesso das negociações levou o governo brasileiro, com base no art. 31 do Acordo TRIPS, a declarar o Efavirenz como de interesse público, por meio da Portaria 886, de 24 de abril de 2007. Com a caracterização do medicamento como de interesse público, a multinacional Merck contou com um prazo de sete dias para apresentar uma nova proposta, a qual não foi aceita pelo governo brasileiro. Assim, em 4 de maio de 2007, o Presidente da República concedeu o licenciamento compulsório para fins de uso público não-comercial das patentes do Efavirenz. Esta forma de licenciamento compulsório, com a caracterização da droga como de interesse público, implica em que não haja prejuízo da remuneração de direito do titular da patente

(27) Portaria n. 985, publicada no DOU de 27 de junho de 2005. 
dicamentos resultantes da associação dos princípios ativos do Lopinavir e do Ritonavir. De fato, a viabilidade do programa de combate à AIDS foi ameaçada por causa do preço de compra do Kaletra, considerando o crescimento do número de pessoas incluídas no programa(28).

O direito à saúde para toda a população é um dever do Estado, segundo o art. 196 da Constituiçao Federal brasileira. Assim, assumir a gratuidade e universalidade do tratamento aos soropositivos e aidéticos, em virtude da Lei Federal n. 9.313, de 13 de novembro de 1996, que dispõe sobre a distribuição gratuita de medicamentos, também implicava em garantir a perenidade do programa de combate à AIDS, o que foi possível graças a uma redução significativa do preço do Kaletra. Contando com o apoio da sociedade civil internacional e da OMC ${ }^{(29)}$, o governo brasileiro anunciou em 8 de julho de 2005 que havia chegado a um acordo com o laboratório $\mathrm{Abbott}^{(30)}$. No mesmo dia, houve uma mudança ministerial e o recém-empossado ministro anunciou que pretendia dar continuidade às negociações com a Abbott, argumentando que nenhum acordo escrito havia sido assinado ${ }^{31}$. No dia 11 de agosto de 2005, o Conselho Nacional de Saúde - órgão ligado ao Ministério - aprovou, por unanimidade, uma resolução(32) recomendando ao governo:

— o fim das negociações ;

- o licenciamento compulsório, não apenas do Lopinavir/r, mas também, do Efavirenz e do Tenofovir, além de qualquer outro medicamento patenteado utilizado no tratamento da AIDS, cujo preço de compra fosse considerado excessivo; e

- a fabricação local destes medicamentos.

De toda forma, o governo brasileiro optou por seguir com as negociações e, em outubro de 2005, assinou um contrato com o laboratório Abbott. Pelos termos do contrato, a multinacional ficou obrigada a reduzir siginificativamente o preço, por unidade, de duas formulações antigas do Kaletra (cápsulas e comprimidos) e, com relação à nova fórmulação, acordou-se uma diminuição no preço por unidade, considerando uma quantia predefinida de 2.830 .680 cápsulas a ser comprada pelo governo brasileiro. Além disso, o laboratório se comprometeu a fornecer gratuitamente sua formula-

(28) Art. 10: "Declara, para fins de sustentabilitade social do programa brasileiro de combate à AIDS, interesse público relativamente aos medicamentos advindos da associação dos princípios ativos Lopinavir e Ritonavir, com vistas à composição do rol dos inibidores de protease que devem compor o arsenal terapêutico para o tratamento da infecção por HIV/AIDS no Brasil".

(29) "OMC parabeniza o Brasil por ter quebrado a patente de drogas contra a AIDS - the breaking of the patent of the aids medicine", publicado em 29 de junho de 2005 no site: ESTADÃO. <http:// www.estadao.com.br/nacional/noticias/2005/jun/29/161.htm>.

(30) Cf. Le Monde de 12 de julho de 2005.

(31) "Brazil's corruption scandal may deal a blow to intellectual property rights", The Economist, July 21 st 2005.

(32) Resolução CNS n. X. 
ção oral para uso pediátrico. Como contrapartida, o governo brasileiro concordou em distribuir o medicamento apenas para pacientes brasileiros e a não exportar o produto. Também firmou compromisso de respeitar " integralmente " os direitos de propriedade intelectual relativos aos princípios ativos do Lopinavir e do Ritonavir. Além disso, o contrato estipulou que a Abbott não oferecia nenhuma assistência para a produção da droga, o que excluiu qualquer forma de transferência de tecnologia durante a validade do contrato, 31 de dezembro de $2001^{(33)}$.

Assim, o país procurou se beneficiar das exigências e das flexibilidades clássicas do direito de patentes, de uma maneira que prometia facilitar o acesso aos medicamentos. O Brasil avançou ainda mais neste caminho ao oferecer às instituições públicas modalidades de intervenção originais na outorga de patentes farmacêuticas.

\section{B. A intervenção original das instituições públicas na outorga de patentes farmacêuticas}

A Lei Federal n. 9.279 criou dois mecanismos interessantes enquanto limitadores da outorga de patentes na área farmacêutica: a submissão à Agência Nacional de Vigilância Sanitária (ANVISA) da outorga de títulos de patentes (a) e o direito de que as instituições públicas, como, por exemplo, o laboratório Far-Manguinhos, de participarem do processo de avaliação de concessão de patente (b).

\section{A anuência prévia da ANVISA na outorga de títulos de patente}

Em 14 de dezembro de $1999^{(34)}$, o art. 229-C fo incluído na Lei Federal n. 9.279, estabelecendo um dispositivo inédito ${ }^{(35)}$. Por este artigo, a concessão de patentes farmacêuticas ficava submetida à anuência prévia da ANVISA ${ }^{(36)}$.

(33) Note-se que o contrato foi duramente atacado pelas ONGs brasileiras que atuam na área de combate à AIDS. De acordo com estas entidades, o percentual fixo para a redução do preço do medicamento segue em direção contrária a toda lógica econômica. Além disso, o Brasil tornou-se dependente da tecnologia da Abbott ao aceitar a cláusula que exclui toda possibilidade de transferência de tecnologia para a produção do Kaletra. Ainda segundo as ONGs, o contrato não garante nem a sobrevivência financeira do programa brasileiro de combate à AIDS, nem a inclusão de novas doenças. Numa tentativa de pressionar o governo a fazer o licenciamento compulsório do Kaletra, estas entidades realizaram uma manifestação em 10. de dezembro de 2005 (Dia Mundial de Combate à AIDS).

(34) Medida Provisória n. 2.006, publicada no D.O.U. de 15 de dezembro de 1999.

(35) De fato, o mecanismo é inexistente nas legislações de outros países do mundo. Fonte: Instituto Dannemann Siemsen de Estudos de Propriedade Intelectual. Comentários à Lei da Propriedade Industrial. Rio de Janeiro: Renovar, 2005. p. 492.

(36) Art. 229-C. "A concessão de patentes para produtos e processos farmacêuticos dependerá da prévia anuência da Agência Nacional de Vigilância Sanitária (ANVISA)". 
A justificativa era a de que o Instituto Nacional da Propriedade Industrial (INPI) não tinha conhecimento técnico específico na área farmacêutica e, dessa forma, não seria possível deixar totalmente a seu cargo a concessão de patentes dentro de um setor tão sensível como o da saúde pública. Dessa maneira, pareceu oportuno confiar a avaliação dos pedidos de patentes de medicamentos ao INPI, como previsto no art. 240 da Lei n. 9.279, e também ao órgão encarregado de autorizar a comercialização de medicamentos ${ }^{(37)}$. A anuência prévia da ANVISA constitui, desde então, um estágio suplementar dentro do processo de patenteamento. Este mecanismo jurídico - se bem que controverso, tanto do ponto de vista do processo legislativo utilizado para sua implementação ${ }^{(38)}$, como de sua compatibilidade com as regras do Direito Internacional ${ }^{(39)}$ - foi ratificado pela Lei $n$. 10.196, de 14 de fevereiro de 2001(40).

Ao adotar tal mecanismo sui generis de avaliação de pedidos de patentes para produtos e processos farmacêuticos, o Brasil deixa clara sua disposição em considerar a proteção da saúde pública na aplicação do direito de patentes, no mais, uma preocupação constante da legislação brasileira.

Em nível constitucional, o país apresenta certa particularidade de ter incluído em sua Constituição de 1988 uma disposição atípica que, rompendo com o argumento de neutralidade histórica do direito de patentes, submete este último ao desenvolvimento social, econômico e tecnológico. Quando tradicionalmente, a função das patentes reside na recompensa única da inovação(41), o art. 5-XXIII reconhece a função social da propriedade ${ }^{(42)}$ e o art. 5-XXIX impõe que, de uma maneira ou de outra, seja criada uma relação entre a invenção, da qual o patenteamento é reivindicado, e os interesses sociais, econômicos e tecnológicos brasileiros ${ }^{(43)}$. Partindo do princípio da hierarquia das normas jurídicas, esta preocupação encontra-se no direito de

(37) Cf. BASSO, M. A Anvisa e a concessão de patentes farmacêuticas. Publicado em 18 de outubro de 2004 no site: <www.tecpar.br>.

(38) O art. 62 da Constituição Federal Brasileira de 1988 dispõe que o Presidente da República pode adotar medidas provisórias em casos de especial importância ou de urgência. Na verdade, a controvérsia girou em torno da legitimidade de se utilizar este instrumento legislativo.

(39) Cf., por exemplo, M. Lobo de Freitas, "Bis in idem", publicado em 29 de junho de 2004 no site: AOL. <http://noticias.aol.com.br/negocios/industria/2004/06/0009.adp>; Instituto Dannemann Siemsen de Estudos de Propriedade Intelectual. Comentários à Lei da Propriedade Industrial, cit., p. 492; D. Barbosa, "A inconstitucionalidade de anuência da ANVISA no procedimento de concessão de patentes como manifestação discricionaria da Administração Federal", julho de 2004. Acreditamos que, de qualquer maneira, este tipo de controle pode entrar no campo da aplicação do art. 18 do Acordo TRIPS que reconhece, explicitamente, o direito dos Estados-memrbos da OMC de adotar políticas que atendam às necessidades de saúde pública.

(40) Lei Federal n. 10.196, publicada no D.O.U. em 16 de fevereiro de 2001.

(41) B. Remiche et H. Desterbecq, préc., p. 11.

(42) Art. 5-XXIII: "A propriedade atendera a sua função social".

(43) Art. 5-XXIX: "A lei assegura aos autores de inventos industriais privilégio temporário para sua utilização, bem como proteção às criações industriais, [...], tendo em vista o interesse social e o desenvolvimento tecnológico e econômico do Pais". 
patentes e, mais precisamente, no coração do art. 240 da Lei n. 9.279, a mesma que conferiu ao INPI a competência de aplicar, no plano nacional, as leis que regem a propriedade industrial, considerando as funções sociais, econômicas, jurídicas e técnicas ${ }^{(44)}$. Assim, ao submeter o patenteamento dos medicamentos à anuência prévia da ANVISA, o Estado reconhece a natureza particular deste produto, mais especificamente, sua importância para a vida e para a sociedade ${ }^{(45)}$. Este mecanismo reflete perfeitamente a disposição do governo brasileiro de atuar em favor do acesso aos medicamentos, disposição ilustrada pela implantação, em 1996, do programa de acesso universal e gratuito às drogas anti-retrovirais.

Concretamente, desde 14 de dezembro de 1999, as solicitações de patentes relativas aos produtos e processos farmacêuticos são submetidos ao crivo do INPI, depois à ANVISA, sendo que ambos avaliam os critérios clássicos de patenteabilidade (novidade, atividade inventiva e aplicação industrial) ao mesmo tempo, com a diferença que a Agência faz este exame à luz das exigências sanitárias. Pode-se lamentar a falta de uma norma jurídica precisa relativa aos quesitos de avaliação da ANVISA, o que cria uma certa insegurança jurídica. As únicas diretrizes sobre o assunto, publicadas em 12 de abril de 2005 na página da internet da ANVISA, recomendam à agência para que tome como base os requisitos de patenteabilidade definidos pela lei de propriedade intelectual(46). Além disso, o caráter de facto aleatório da autorização da Agência pode afetar a legitimidade de tal controle. Sem a anuência prévia da ANVISA, não se outorga uma patente farmacêutica(47). Assim, a agência tem um papel primordial e limitante do campo de patenteamento de produtos e processos farmacêuticos. De fato, ela pode interpretar de uma maneira mais restrita os critérios clássicos de patenteabilidade e, desse modo, excluir as mee-too drugs ${ }^{(48)}$, as associações de componentes conhecidos - à semelhança das triterapias - e as segundas indicações terapêuticas ${ }^{(49)}$ da patenteabilidade (note-se que o Acordo TRIPS não trata desta matéria, o que oferece toda a liberdade aos Estados-membros de conceder ou não os títulos de patentes a estes tipos de invenções). Nestes casos, os medicamentos não são protegidos pelas patentes e podem ser

(44) Art. 24. "O INPI tem por finalidade principal executar, no âmbito nacional, as normas que regulam a propriedade industrial, tendo em vista a sua função social, econômica, jurídica e técnica, bem como pronunciar-se quanto à conveniência de assinatura, ratificação e denúncia de convenções, tratados, convênios e acordos sobre propriedade industrial".

(45) RODRIGUES, E. Beas. Anuência prévia: integração do direito à saúde aos direitos de propriedade intelectual. out. 2005. p. 3.

(46) As diretrizes dispõem o seguinte: "a Anvisa esclarece que todas as análises realizadas pela Anvisa tem por base exclusivamente os requisitos legais previstos nos instrumentos vigentes sobre o tema".

(47) RODRIGUES, E. Beas. op. cit., préc., p. 7.

(48) Um me-too drug é um medicamento cuja organização do composto químico é estruturalmente muito similar a uma droga já conhecida e que apresenta diferenças farmacológicas pequenas.

(49) Trata-se de uma nova indicação terapêutica para um produto que já tem uso farmacêutico conhecido. 
fabricados localmente a custos freqüentemente inferiores aos praticados pelo mercado. Nesta situação, a Agência também atua como facilitadora do acesso aos medicamentos.

Na prática, desde 2004, a ANVISA não concede anuência prévia a uma segunda indicação terapêutica. Uma nota técnica de 25 de agosto de 2004(50) interdita a patenteabilidade a tais invenções, pois, de um lado, elas não preenchem o critério de novidade e, por outro, elas prejudicam o acesso aos medicamentos. A exclusão das segundas indicações terapêuticas do domínio da patenteabilidade implica na seguinte conseqüência : uma droga patenteada, para a qual se descobrem novas indicações terapêuticas, durante ou após o período de proteção conferida pela patente, poderá ser produzida como droga genérica, desde o fim de sua patente no domínio público, sendo que as novas indicações terapêuticas não geram direito a uma nova proteção.

Este exemplo mostra que a ANVISA é dotada de um poder de regulação sobre a patenteabilidade dos medicamentos e participa da promoção da saúde pública.

De qualquer forma, este controle, que poderia ser qualificado de "sanitário", não é exercido sem se considerar as diferenças entre o INPI e a agência. O instituto optou por uma posição menos radical do que a da ANVI$S A^{(51)}$, considerando que o Brasil, como um país emergente, tem todo o interesse em reconhecer a patenteabilidade das segundas indicações terapêuticas, pois este tipo de invenção constitui um nicho de mercado. Suas guidelines têm como objetivo desenvolver a indústria brasileira, enquanto país exportador de tecnologia e se opõem às da ANVISA, que privilegiam o interesse sanitário sobre os interesses econômicos das empresas. Pode-se observar que a resolução de tais litígios não foi organizada de um ponto de vista jurídico. É por essa razão que, na prática, as reuniões técnicas de especialistas são realizadas para harmonizar in concreto as divergências de visões entre as duas instituições ${ }^{(52)}$. Por falta de consenso, como mencionado anteriormente, a posição da ANVISA prevalece, pois a anuência prévia é necessária para a concessão da patente farmacêutica.

O poder regulador exercido pela ANVISA foi legitimado por uma decisão judicial recente, opondo a Aventis Pharma ao INPI e à agência ${ }^{(53)}$. $O$ laboratório contestava a negação da anuência prévia e, conseqüentemente, a da patente. A 38 ${ }^{\text {a }}$ Vara Federal do Rio de Janeiro, com base no art. 5-XXIX

(50)ANVISA. Esclarecimentos sobre pedidos de patentes dos produtos e processos farmacêuticos. Disponível em: <http://www.anvisa.gov.br/divulga/alertas/2004/250804.htm>.

(51) Diretrizes para avaliação de solicitações de patentes de biotecnologia e farmacêuticas depositadas após 31 de dezembro de 1994, publicadas no site: Disponível <http://www.agif.com.br/ download/INPI-diretrizes\%20para\%20exame.doc>.

(52) O que representa de $4 \%$ a $5 \%$ dos pedidos de patentes farmacêuticas, segundo informações da ANVISA.

(53) Processo n. 2004.51.01.513854-1, de 5 setembro de 2005. 
da Constituição, decidiu que os direitos de propriedade intelectual não poderiam ser concedidos no Brasil, a não ser que o interesse social, econômico e tecnológico do país fosse respeitado. A decisão justifica a intervenção da ANVISA dentro do processo de análise das solicitações de patentes para invenções farmacêuticas. A argumentação da Corte foi a seguinte: no segmento de medicamentos, a anuência da agência é legítima, pois ela permite verificar se os pedidos de patentes respondem aos critérios de patenteabilidade e aos objetivos de proteção da saúde pública do país. Se os requisitos de patenteabilidade não são estritamente preenchidos, a agência pode dar não dar a anuência prévia e impedir o patenteamento da invenção.

A ANVISA não é a única instituição pública que conta com o poder de controle em relação à concessão de patentes farmacêuticas. O laboratório público Far-Manguinhos pode igualmente participar deste processo.

\section{O papel do laboratório público Far-Manguinhos}

Criado em 1956, Far-Manguinhos é o laboratório oficial do Ministério da Saúde. Considerado centro de referência em pesquisa e desenvolvimento de tecnologia e produção farmacêutica no Brasil, a instituição tem um papel essencial na problemática do acesso aos medicamentos contra a AIDS. Ele foi o primeiro laboratório público a fabricar os anti-retorvirais (ARVs) ditos "similares"(54), atendendo às necessidades do programa de combate à doença. É preciso destacar que, no Brasil, desde da edição da Lei n. 9.313, de 13 novembre 1996, a distribuição de ARVs é gratuita e universal para todo o portador do vírus HIV ou da doença e é feita pelo Sistema Único de Saúde (SUS), estabelecido em uma rede de laboratórios públicos, responsáveis pela fabricação, a pedido do Ministério da Saúde, de medicamentos essenciais e de ARVs. Encorajando a produção endógena de drogas similares - cópias de medicamentos que não são patenteados no Brasil ou cuja patente caiu em domínio público esta política sanitária tem dois lados interessantes: primeiro, ela permite redução de custos, e, segundo, ela estimula a pesquisa e o desenvolvimento das capacidades farmacêuticas locais ${ }^{(55)}$, como é o caso do Far-Manguinhos.

$\mathrm{O}$ art. 31 da Lei n. 9.279 confere ao laboratório o direito de participar da avaliação dos pedidos de patentes. De fato, toda parte interessada no pedido da pentente, pode se pronunciar sobre o processo, desde a publicação do pedido até o fim da avaliação, colaborando com informações para facilitar o exame da solicitação(56).

(54) Far-Manguinhos não produz medicamentos genéricos, mas similares, os quais não são submetidos aos testes de bioequivalência e biodisponibilidade.

(55) BERNARDES, Marques M. Saúde pública, ética e mercado no entreato de dois séculos. São Paulo: Brasiliense, 2005. p. 77.

(56) Art. 31. "Publicado o pedido de patente e até o final do exame, será facultada a apresentação, pelos interessados, de documentos e informações para subsidiarem o exame". 
Se esta disposição não é exatamente original - vários países contam com este tipo de medida legal - , sua utilização é notável. Seu campo de aplicação revela um caráter abrangente, uma vez que, ela demonstra uma abordagem particular nos exames dos pedidos de patentes que inclui, não apenas os interesses das instituições privadas, como também aqueles das públicas.

Este direito de participação do Far-Manguinhos foi exercido em 6 de dezembro de 2005 para contestar a demanda de patente do Tenofovir(57), depositada em 1998, pela Gilead Sciences, Inc ${ }^{(58)}$. A molécula em questão apresentava um caráter de tratamento de "segunda linha" ou de "segunda geração", que substituía as triterapias originais, em razão do aumento do número de pacientes que desenvolveram resistência às moléculas de primeira geração e dos pacientes nos quais a terapêutica fracassou (as triterapias de primeira linha não funcionaram). Bem, uma patente concedida para este tipo de molécula implicaria em um preço elevado de venda. $E$, a não concessão da patente permitiria aos laboratórios brasileiros produtores de genéricos, Far-Manguinhos entre eles, de fabricar cópias menos onerosas. Compreende-se perfeitamente a motivação para a ação do laboratório.

Concretamente, o Far-Manguinhos apresentou um dossiê ao INPI para demonstrar a falta de atividade inventiva do Tenofovir, argumentando que para poder ser patenteada, uma invenção deveria atender aos três critérios enunciados no art. $8^{\circ}$ da Lei n. 9.279: novidade, atividade inventiva, aplicação industrial. Segundo o art. 13 desta mesma lei, atividade inventiva é definida como sendo uma atividade que não decorra de maneira evidente do estado da técnica ${ }^{(59)}$. O estado da técnica é constituído de tudo o que foi colocado à disposição pública, antes da data de depósito do pedido da patente, por descrição oral ou escrita, para uso ou para qualquer outro meio, no Brasil ou no exterior(60). Ora, uma pesquisa de anterioridade feita pelo Far-Manguinhos, mostrou que, em primeiro lugar, o Tenofovir apresentava apenas uma ligeira modificação em relação a outras moléculas, conhecidas e patenteadas nos Estados Unidos, mas não no Brasil, e que esta alteração decorreu de maneira evidente do estado da técnica. De fato, a técnica de obtenção do medicamento tinha sido descrita em artigos científicos e em pedidos de patentes de moléculas análogas e, dessa maneira, qualquer especialista farmacêutico poderia livremente reproduzi-la. Pode-se questionar qual seria a posição do INPI face a esses argumentos.

(57) O Tenofovir é um inibidor da transcriptase inversa, indicado em associação com outros ARVs, para o tratamento dos doentes infectados pelo vírus $\mathrm{VIH}-1$ que não responde a outros tratamentos.

(58) Pedido de patente n. PI9811045-4.

(59) Art. 13. "A invenção é dotada de atividade inventiva sempre que, para um técnico no assunto, não decorra de maneira evidente ou óbvia do estado da técnica".

(60) Art. 11, §1:: "O estado da técnica é constituído por tudo aquilo tornado acessível ao público antes da data de depósito do pedido de patente, por descrição escrita ou oral, por uso ou qualquer outro meio, no Brasil ou no exterior, ressalvado o disposto nos arts. 12, 16 e 17". 
Assim, o Brasil buscou integrar os padrões internacionais de uma maneira que se promovesse, apesar de tudo, o acesso aos medicamentos de forma não tão onerosos. Porém, o país ainda não teve sucesso completo neste caminho, pois certas disposições se mostraram insuficientes do ponto de vista das necessidades da saúde pública.

\section{AS LACUNAS NA LEGISLAÇÃO BRASILEIRA}

Como dito, embora a legislação brasileira parecesse integrar os prérequisitos internacionais, em matéria de propriedade industrial, de uma maneira que afetasse o menos possível o acesso aos medicamentos, o Brasil não chegou a alcançar completamente este objetivo, pois o país, não apenas, aplicou a legislação internacional de uma maneira mais estrita $(A)$, como também não agregou certas flexibilidades importantes (B).

\section{A. O Brasil além das limitações internacionais}

Como país em desenvolvimento, o Brasil poderia levar mais tempo para se adaptar à legislação internacional sobre propriedade industrial. Porém, escolheu se adequar às conformações previstas no Acordo TRIPS já em 1996 (1). E, além disso, o país instaurou um sistema de proteção de "patentes pipelines" não previsto pela normas mundiais (2).

\section{Uma aplicação precoce da legislação internacional}

O Acordo TRIPS previu disposições transitórias relativas a sua aplicação, considerando os diferentes níveis de desenvolvimento dos Estadosmembros ${ }^{(61)}$ : as nações desenvolvidas tinham um ano para se adequar ao acordo; os países em desenvolvimento, cinco anos e as nações mais pobres, dez anos. Por outro lado, as disposições transitórias especiais se aplicavam nos casos de países em desenvolvimento que não tinham normas para a proteção de patentes farmacêuticas. Nesta hipótese, eles dispunham também de um período adicional de cinco anos para organizar um sistema de proteção(62). Assim, Brasil, Índia e outras nações do mesmo nível de desenvolvimento tinham até $1^{\circ}$ de janeiro de 2005 para modificar suas legislações.

(61) Arts. 65 e 66 do Acordo TRIPS.

(62) Art. 65-4 do Acordo TRIPS dispõe que: "Na medida em que um País-membro em desenvolvimento esteja obrigado pelo presente Acordo a estender proteção patentária de produtos a setores tecnológicos que não protegia em seu território na data geral de aplicação do presente Acordo, conforme estabelecido no parágrafo 2, ele poderá adiar a aplicação das disposições sobre patentes de produtos da Seção 5 da Parte II para tais setores tecnológicos por um prazo adicional de cinco anos". 
Elas poderiam se beneficiar deste tempo para desenvolver a indústria de genéricos e produzir cópias de medicamentos a baixo preço. Porém, se os indianos utilizaram plenamente esta vantagem ${ }^{(63)}$, o Brasil reconheceu a patenteabilidade dos produtos farmacêuticos já em 14 de maio de 1996, com a Lei n. 9.279.

Esta estratégia surpreendente se explica pelas pressões exercidas pelo governo norte-americano, desde 1987, sob a proteção da Seção 301 do Ato sobre Tarifas e Comércio (1984)(64). Em 11 de junho de 1987, a PhRMA ${ }^{(65)}$ associação que agrupa as principais indústrias farmacêuticas dos Estados Unidos - encaminhou uma petição ao governo daquele país, acusando o Brasil de não agir de maneira adequada com relação ao reconhecimento das patentes farmacêuticas ${ }^{(66)}$.

O órgão do governo norte-americano responsável por questões comerciais (Office of the United States Trade Representative - USTR) classificou o Brasill na categoria "país estrangeiro prioritário" e deu início a suas investigações sobre o caso. O governo brasileiro, desejoso de encontrar uma solução para o conflito, anunciou, em junho de 1988, uma reforma legislativa sobre o patenteamento de produtos farmacêuticos. Esta revisão foi considerada insatisfatória pelos Estados Unidos que aplicaram medidas de retaliação comercial (uma tarifa de $100 \%$ ad valorem) sobre certos tipos de papéis, produtos químicos e artigos eletrônicos brasileiros.

Em junho de 1990, com as eleições para a presidência do Brasil, um novo governo tomou posse e propôs uma reforma na legislação com relação à propriedade industrial que resolveu o impasse e cessou com as sanções comerciais. Porém, em abril de 1993, a Câmara Federal rejeitou esta proposta de mudança por discordar sobre a extensão das patentes e dos direitos dos titulares ${ }^{(67)}$. Este ato deu início a novas tensões com os Estados Unidos que declarou que ou o Brasil reconhecia as patentes dos produtos farmacêuticos, até fevereiro de 2004, ou novas investigações e sanções seriam aplicadas. As negociações brasileiras resultaram na adoção da Lei $n$. 9.279, um compromisso entre Brasil e EUA, ou, mais especificamente, entre os interesses nacionais e as exigências das empresas multinacionais. A

(63) A Índia modificou sua legislação sobre propriedade industrial em 25 de março de 2005.

(64) Barbosa, D. Uma introdução à propriedade intelectual. 2. ed. Rio de Janeiro: Lumen Juris, 2003. p. 7.

(65) Pharmaceutical Research and Manufacturers of America.

(66) A razão do conflito estava no fato de que o Brasil representava um mercado muito importantes para os investidores norte-americanos ( $7^{\circ}$ colocado no mundo). Cf. Tachinardi, M. A guerra das patentes: o conflito Brasil \& EUA sobre Propriedade Intelectual. Rio de Janeiro: Paz e Terra, 1993.

p. 112.

(67) Os pontos de divergência eram a patenteabilidade ou não dos seres vivos (microorganismos, plantas e animais) e dos medicamentos essenciais, a proteção das patentes de pipelines, a duração da proteção concedida pelas patentes, os requisitos para a concessão de licença compulsória e as importações paralelas. 
evocação deste velho conflito explica porque o Brasil não se beneficiou das disposições transitórias especiais, previstas no Acordo TRIPS.

Além disso, ainda adotou uma série de medidas - não preconizadas no TRIPS - de maneira a proteger os "patentes pipelines".

\section{As medidas de proteção de patentes de pipelines ${ }^{(68)}$}

O Acordo TRIPS não previa medidas relativas às patentes de pipelines, se bem que os Estados Unidos reivindicaram esta proteção durante toda a Rodada do Uruguai(69). No caso, tratava-se de uma proteção retroativa de medicamentos já patenteados em outros países ${ }^{(70)}$. Vista a constante preocupação norte-americana com relação à proteção patentária em geral, e com a área farmacêutica em particular, e vistas as pressões exercidas pelo governo daquele país, pode-se bem imaginar que o Brasil foi forçado a organizar o sistema de proteção patentária de pipelines.

De real, a legislação brasileira de 1996 criou um mecanismo temporário de patentes de pipeline dentro do Título VIII, relativo às disposições transitórias e finais ${ }^{(71)}$. Por conta deste mecanismo, uma patente poderia ser conferida a uma invenção da área farmacêutica ${ }^{(72)}$, desde que ela já tenha sido dada pelo país do primeiro pedido, na condição de que o objeto da patente não tenha sido comercializado no Brasil pelo titular da patente ou por autorização sua. Em outros termos, as patentes podiam ser concedidas às invenções que já haviam sido divulgadas e que não podiam mais preencher, de fato, o critério de novidade. Note-se que estas patentes eram dadas de maneira automática, sem exame técnico (i. e. sem pesquisa sobre os critérios de patenteabilidade), a partir do momento em que elas tivessem sido concedidas no exterior, ou seja, no mesmo tempo em que são outorgadas as patentes originais.

(68) As patentes de pipelines são portfólios de moléculas patenteadas, ainda não comercializadas, as quais os laboratórios dispõem.

(69) Mondialisation et accès aux médicaments: perspectives sur l'accord ADPIC de l'OMC. Programme d'Action pour les Médicaments Essentiels, 1999. p. 51. (Série Économie de la Santé et Médicaments, n. 7.

(70) Atenção para não confundir este mecanismo com o sistema de "boîte aux lettres" previsto no art. 70.8 do TRIPS, que trata dos países que não reconheceram a proteção patentária das invenções farmacêuticas em 10. de janeiro de 1995, independentemente do período de transição que Ihes foi acordado. Eles devem implementar, a contar desta data, uma infra-estrutura adequada para receber os pedidos de patentes. Este artifício jurídico pemitiu preservar a novidade das invenções descobertas a partir de 1995, mas que não conseguiram receber patente antes de 12 anos no máximo. Se a solicitação preenchia corretamente os três critérios de patenteabilidade, avaliados na data do depósito, a patente era concedida por um período de 20 anos, iniciando-se a partir da data do depósito.

(71) Arts. 229, 230 e 231 da Lei n. 9.279.

(72) $\mathrm{Na}$ realidade, o mecanismo se aplica aos produtos e processos químicos e alimentares. 
A patende de pipeline representa então uma exceção ao conceito clássico de proteção patentária, uma vez que ela funciona como uma "revalidação" das patentes adquiridas no exterior ${ }^{(73)}$. Este mecanismo jurídico se aplica também às patentes nacionais (sendo que, neste caso, a data de depósito conta a partir da data da primeira divulgação da invenção e os pedidos são instruídos conforme os critérios clássicos de patenteabilidade).

A patente concedida em virtude desta proteção é outorgada por uma duração equivalente ao tempo que resta para expirar a patente no país onde foi feito o primeiro pedido ${ }^{(74)}$.

Além disso, a patente de pipeline não tem validade para solicitações apresentadas entre a data de promulgação e a data de entrada em vigor da lei(75).

Enfim, note-se que este mecanismo jurídico foi objeto de vivas controvérsias entre as instituições científicas brasileiras, a sociedade civil e as empresas nacionais ${ }^{(76)}$, pelo fato de que previa uma proteção superior àquela exigida pelo TRIPS(77). Certos autores, como Carlos Correa, até mesmo denunciaram a inconstitucionalidade da lei e invocaram sua incompatibilidade com o critério de novidade: "thus, the US government and the pharmaceutical industry have attempted to obtain a retroactive recognition of protection for pharmaceuticals that are already patented (the so-called "pipeline" protection). The Andean Court of Justice (established by the Cartagena Agreement) declared in a decision (Process $n$. 1-Al-96) on 30 October 1996, that the "pipeline" formula was inherent contradictory with the novalty requirement under patent law, and thus rejected the retroactive registration of patents in the subregion. ${ }^{(78)}$

Assim, o Brasil aplicou a máxima legislação internacional, com sua adaptação imediata aos padrões mundiais e a criação da patente de pipeline.

(73) Instituto Dannemann Siemsen de Estudos de Propriedade Intelectual. Comentários à Lei da Propriedade Industrial, cit., p. 493.

(74) Art. 230-4 da Lei n. 9.279.

(75) Art. 230-1 da Lei n. 9.279.

(76) Disse José Serra, Ministro da Saúde, na época: "A incorporação do mecanismo do pipeline à lei de patentes foi uma concessão desnecessaria feita pelo Brasil, dado que não era uma exigência do Acordo TRIPS, sendo alvo de críticas até hoje." CORREA, Carlos. El Acuerdo TRIPs. Buenos Aires: Ed. Ciudad Argentina, 1996, confirma tal declaração: "el Acuerdo adopto una posición a dicho reconocimiento, rechazando soluciones tipo "pipeline". Los articulos 70.1 y 70.3 disponen al respecto que el Acuerdo no genera obligaciones relativas a actos realizados antes de la fecha de aplicación del Acuerdo para Miembro (art. 70.1) y no obliga a restabelecer la protección de la materia que en esa fecha haya pasado al dominio publico (art. 70.3)."

(77) Bermudez, J.; Epstejn, R.; Oliveira, M.; Hasenclever, L. The WTO TRIPS Agreement and Patent Protection in Brazil: recent changes and implications for local production and access to Medicines. Rio de Janeiro: WHO/PAHO/ENSP, Apr. 2000. p. 70.

(78) Barbosa, D. op. cit., p. 639. 


\section{B. Uma transposição inalcançada de mecanimos que favorecem o acesso aos medicamentos}

Além do licenciamento compulsório, o Acordo TRIPS permite outra flexibilidade clássica destinada a facilitar o acesso aos medicamentos: as importações paralelas. A decisão de 30 de agosto de 2003 definiu um mecanismo jurídico original que favoreceu o fornecimento de drogas genéricas aos países mais pobres e, indiretamente, o desenvolvimento da indústria de genéricos. Ora, o Brasil não aproveitou plenamente esta flexibilidade, pois não explorou satisfatoriamente este mecanismo (1) e não adotou a decisão de agosto de 2003, perdendo assim uma oportunidade (2).

\section{Importações paralelas severamente limitadas}

O mecanismo de importação paralela tem como base a doutrina alemã de exaustão do direito de patente, fundada por Kohler e a decisão Reisgericht, de 26 de março de 1902 que enuncia: "a patente de um procedimento tem por conseqüência que ninguém, além do titular (e daqueles autorizados por ele), pode fabricar o produto de acordo com este procedimento e comercializá-lo no país. Esta situação, no entanto, provoca a exaustão do efeito da proteção concedida pela patente. O titular que fabrica e comercializa o produto, sob esta forma de proteção que exclui a concorrência, conta com vantagens que o patenteamento proporciona e, dessa maneira, utiliza todos os recursos derivados do registro da patente, fazendo uso integral de seu direito. A patente não garante ao seu titular, porém, o poder de submeter a circulação do produto a condições determinadas. ${ }^{(79)}$

Dessa maneira, em virtude desta construção jurídica, o inventor é recompensado pelo seu esforço criativo no momento em que ele comercializa pela primeira vez sua invenção. A partir desta primeira comercialização, seus direitos são considerados "esgotados". Ele não pode mais proibir a livre circulação de sua invenção, nem a importação paralela do produto, com base na proteção patentária. Esta visão limitada do direito de patente apresenta uma considerável importância dentro do comércio internacional.

$\mathrm{Na}$ prática, as importações paralelas resultam de estratégias empresariais de fixação de preços em função dos diferentes mercados. No setor farmacêutico, estas estratégias consistem em uma operação pela qual "um importador compra um determinado medicamento, de um país que fabrica ou vende a droga por um preço baixo, e comercializa este mesmo produto em um país no qual seu preço é mais elevado, se beneficiando de uma diferença de valores"(80).

(79) Cf. Foyer, J.; Vivant, M. Le droit des brevets. Paris: Thémis, 1990. p. 327.

(80) Definição de VIALA, G.; BURTIN, J.-F. La libre circulation des médicaments et ses limites, au travers de la jurisprudence de la Cour de justice des Communautés européennes. RD San. Soc. V. 34, n. 1, p. 81, janv./mars 1998. 
Esse tipo de comércio permite aos intermediários - aproveitando as estratégias comerciais dos laboratórios farmacêuticos - importar medicamentos a custos mais baixos. Dessa maneira, as importações paralelas oferecem aos consumidores melhores preços dentro do mercado mundial para uma droga patenteada ${ }^{(81)}$. Assim, impedem os detentores das patentes de segmentar mercados e de discriminar preços em relação a escalas regionais ou internacionais. É desta forma que as importações paralelas contribuem para facilitar o acesso aos medicamentos. Pode-se compreender, perfeitamente, porque os países em desenvolvimento têm interesse em utilizar este mecanismo e em buscar medicamentos com bons preços em todo o mundo.

Se o Acordo TRIPS regula com uma relativa precisão o licenciamento compulsório, ele também faz uma referência bastante pontual à exaustão do direito de patente no art. 6, o qual indica que esta questão não pode ser regulada pelo Memorandum do acordo sobre a regulamentação das diferenças, exceto nos casos de recurso com base em discriminação ${ }^{(82)}$.

Concretamente, isto significa que os Estados-membros podem escoIher o regime relacionado à exaustão de direitos. O TRIPS não impõe, de fato, nenhuma obrigação sobre esta matéria, o que torna a questão de competência puramente nacional. Os Estados-membros têm toda a liberdade para aplicar:

- a exaustão em nível internacional, ou a possibilidade de um terceiro importar em seu território o mesmo produto patenteado proveniente de qualquer outro país onde ele já teria sido comercializado com o consentimento do titular da patente. Este tipo de mecanismo apresenta a vantagem de oferecer medicamentos com os melhores preços; todavia, em detrimento do desenvolvimento da indústria local;

- ou a exaustão em nível regional, como acontece na União Européia ${ }^{(83)}$ : a possibilidade de importar no território de um Estado-membro o mesmo produto patenteado proveniente de qualquer outro país do mesmo bloco regional; ou ainda

- a exaustão nacional que limita o direito de circulação de produtos protegidos por uma patente dentro de um país que se encontra em estado de exaustão nacional. Simplificando, este tipo de mecanismo interdita as importações paralelas.

(81) CORREA, Carlos. Intégration des considérations de santé publique dans la législation en matière de brevets dans les pays en développement. South Centre, nov. 2001. p. 82.

(82) Art. 60: "para os propósitos de solução de controvérsias no marco deste Acordo, e sem prejuízo do disposto nos arts. 3 e 4, nada neste Acordo será utilizado para tratar da questão da exaustão dos direitos de propriedade intelectual".

(83) A Corte de Justiça da Comunidade Européia, com o objetivo de promover a livre circulação de mercadorias no território comunitário, consagrou o princípio da exaustão comunitária dos direitos de patente, segundo o decreto Centrafarm c/ Sterling Drug de 31 octobre 1974 (aff. 15/74: Rec. CJCE 1974, p. 1147). 
O direito brasileiro não faz uso desta flexibilidade do Acordo TRIPS, uma vez que admite apenas a exaustão nacional dos direitos de patente ${ }^{(84)}$, proibindo de fato as importações paralelas ${ }^{(85)}$. Este caso representa a solução menos favorável aos consumidores, pois os direitos de patentes permitem ao governo controlar totalmente a comercialização do produto. Mais uma vez, a solução adotada pelo Brasil mostra-se paradoxal, do ponto de vista da saúde pública.

O princípio de exaustão em nível nacional foi, de toda forma, equilibrado com a possibilidade de algumas exceções. As importações paralelas de produtos ou processos patenteados são autorizadas para permitir a exploração da invenção, em caso de licenciamento compulsório por falta de exploração do produto em território nacional|(86), por abuso de poder econômico ${ }^{(87)}$, e, pelo Decreto n. $4.830^{(88)}$, em razão de deficiência da produção nacional, em uma situação de licenciamento compulsório por urgência nacional ou interesse público ${ }^{(89)}$. Elas também são possíveis quando o detentor da patente autoriza a comercialização do produto. Note-se que, até o momento, nenhuma destas exceções foi colocada em prática.

Outra razão pela qual o Brasil não faz uso pleno do mecanismo de importações paralelas está na falta de regulamentação da decisão de 30 de agosto de 2003 da OMC, relativa ao fornecimento de medicamentos genéricos nos países mais pobres.

\section{A não regulamentação da decisão da OMC de $\mathbf{3 0}$ de agosto de 2003}

A decisão da OMC de 30 de agosto de 2003 derrogou duas obrigações essenciais enunciadas nos parágrafos $f$ e $h$ do Acordo TRIPS, segundo os quais o licenciamento compulsório será autorizado "predominantemente para suprir o mercado interno do Membro que autorizou" e o titular da patente "será adequadamente remunerado nas circunstâncias de cada uso, levando-se em conta o valor econômico da autorização". Assim, esta decisão cria um verdadeiro estatuto diferenciado para os produtos farmacêuticos, na medida em que tais produtos são necessários para resolver problemas de saúde pública, a saber: todo produto farmacêutico patenteado ou todo produto fabricado por meio de um processo patenteado, todos os princípios ativos necessários à sua fabricação e os kits de diagnósticos necessários para sua utlização.

(84) $\mathrm{O}$ art. 42 dispõe que "a patente confere a seu titular o direito de impedir terceiro, sem o seu consentimento, de produzir, usar, colocar à venda, vender ou importar com estes propósitos".

(85) As importações paralelas não são, no entanto, punidas criminalmente, assim quem comete este tipo de infração sofre apenas sanções civis (cf. art. 184 II da Lei n. 9.279).

(86) Cf. art. 68-4 da Lei n. 9.279.

(87) Cf. art. 63-3 da Lei n. 9.279.

(88) Decreto de 4 de setembro de 2003, publicado no DOU em 5 de setembro de 2003.

(89) Cf. arts. 71 da Lei n. 9.279 e do art. 10 do Decreto n. 4.830. 
Concretamente, a decisão instaura um sistema de licenciamentos compulsórios cruzados para permitir aos países pobres, que não têm condições de produzir medicamentos, importar com mais facilidade drogas genéricas com o melhor preço, pois, "para ser eficaz, a licença compulsória deve ser outorgada às indústrias capazes de fabricar medicamentos com rapidez e aos custos mais baixos possíveis". No entanto, tal capacidade de produção não existe na maioria dos países pobres e somente os países emergentes podem utilizar esse recurso efetivamente ${ }^{(90)}$.

Assim, duas categorias jurídicas novas foram criadas para viabilizar este sistema: a de "Membro importador admissível" que inclui países menos avançados e todos os demais Estados-membros da OMC que notificaram ao conselho do Acordo TRIPS a intenção de utilizar o sistema enquanto importador $^{(91)}$ (Alemanha, Austrália, Áustria, Bélgica, Canadá, Dinamarca, Espanha, Estados Unidos, Finlândia, França, Grécia, Irlanda, Islândia, Itália, Japão, Luxemburgo, Noruega, Nova Zelândia, Países Baixos, Portugal, Reino Unido, Suécia e Suiça) e uma outra categoria de "Membro exportador" que se estende aos países que utilizam o sistema para produzir e exportar produtos farmacêuticos para um país considerado um "Membro importador admissível”(92).

O sistema funciona da seguinte maneira: um país importador declarado admissível apresenta ao conselho do TRIPS uma notificação que especifica o nome e a quantidade esperada do medicamento necessário. Este país comprova que o segmento farmacêutico nacional não tem capacidade suficiente de fabricação da droga em questão ${ }^{(93)}$ e indica que aceita uma licença compulsória de importação para o produto. A seguir, um país exportador já determinado pelo importador - informa ao conselho a concessão de uma licença compulsória de exportação. Esta notificação atende aos seguintes requisitos: identificação do detentor da licença, do produto, incluindo a quantidade solicitada, e do país que receberá o medicamento; prazo de duração da licença e endereço na internet que publicará informações referentes a esta licença (quantidade, destino e características da droga). Note-se que esta licença deve atender a condições específicas: o volume do produto fabricado deve corresponder exatamente às necessidades do país importador, a integralidade da produção deve ser exportada e o medicamento deve ser claramente identificado como um produto fabricado dentro das regras deste sistema de importação, por meio de uma etiqueta ou marca específica. O país exportador pode então fabricar e exportar o medicamento para 0

(90) HERMITTE M.-A. Bioéthique et brevets dans le droit du commerce international: la construction d'un nouveau contrat social. In: Maljean-Dubois, S. (Dir.) La communauté internationale et les enjeux bioéthiques. Paris: Pedone, 2005.

(91) Paragráfo 1.b) da Decisão de 30 de agosto de 2003.

(92) Parágrafo 1.c) da Decisão de 30 de agosto de 2003.

(93) Os países menos avançados são qualificados como "Membros importadores admissíveis". 
importador. Em contrapartida, o detentor da patente deve receber uma remuneração "adequada" por parte do exportador, considerando "o valor econômico que representa para o país importador a utilização autorizada pelo exportador"(94).

Para evitar desvios e a reexportação, o país importador deverá implementar medidas segundo suas possibilidades administrativas e os risco de desvios.

Note-se que, por razões econômicas, na hipótese do país importador fazer parte de algum acordo comercial regional, este sistema poderá ser utilizado para fornecer provisões para os mercados de outras nações em desenvolvimento deste mesmo acordo, uma vez que elas compartilham do mesmo problema de saúde pública ${ }^{(95)}$.

Para dirimir os temores de que esta decisão de 30 de agosto pudesse ser utilizada de maneira abusiva, comprometendo assim a proteção patentária, o Presidente do Conselho Geral do TRIPS ${ }^{(96)}$ deu uma declaração que determina que este sistema de importação deverá ser utilizado "com bom senso, para a proteção da saúde da população" e que ele não deverá ser um instrumento de política industrial ou comercial. Além disso, em caso de uma nação exportadora em desenvolvimento, este sistema poderá colaborar para o desenvolvimento da indústria farmacêutica deste país. A declaração insiste, ainda, sobre a necessidade de se prevenir o deturpamento dos produtos, chegando a oferecer diretrizes relativas ás "melhores práticas". Por fim, apela aos membros da OMC a negociar com diligência e cavalheirismo toda questão decorrente da utilização desta possibilidade prevista pela decisão de 30 de agosto de 2003.

Agora, apesar do Brasil parecer preocupado em incluir considerações de ordem sanitária no coração mesmo de sua legislação sobre propriedade industrial, ele não iniciou - até o momento presente - o processo de regulamentação da decisão sobre a implantação do parágrado 6 da Declaração de Doha. Assim, pela falta de uma reforma no Direito brasileiro que integre o sistema proposto pela OMC, o país não pode se beneficiar dele. Rei de todas as formas de desigualdades sociais, o Brasil poderá vir a se arrepender deste imobilismo jurídico.

De qualquer forma, pode-se pensar na hipótese de que o Brasil possa fazer parte deste sistema como um país importador admissível. Admitindose, por exemplo, que ele não disponha de meios suficientes de fabricação de um anti-retroviral de última geração - de um tipo que se constitui como a única solução terapêutica em caso de resistência às triterapias clássicas

(94) Parágrafo 3 da Decisão de 30 de agosto de 2003.

(95) Parágrafo 6. i) da Decisão de 30 de agosto de 2003.

(96) Declaração do Presidente do Conselho Geral de 30 de agosto de 2003 publicada no site: $<$ http://www.wto.org/french/news_t/news03_f/trips_stat_28aug03_f.htm>. 
- em caso de um aumento de epidemia de AIDS, pode-se muito bem imaginar esta situação como uma emergência sanitária. Porém, como o país não integrou as flexibilidades da decisão de 30 de agosto de 2003 em seu Direito interno, ele não poderia fazer uso do sistema para se abastecer, por exemplo, a partir de um fornecedor indiano. Esta possibilidade parece ainda mais plausível, considerando que o Brasil não é um produtor de princípios ativos $^{(97)}$. Assim é surpreendente que o país se prive de um novo instrumento jurídico que colabora para facilitar o acesso aos medicamentos.

Pode-se imaginar uma demanda do Brasil enquanto país exportador. De fato, em vista do sucesso de seu programa de combate à AIDS, o Brasil figura como um exemplo de nível internacional por ter conseguido diminuir consideravelmente a epidemia da doença. Além disso, o país é conhecido por contar com uma capacidade de produção, por meio de seus fortes laboratórios públicos (Far-Manguinhos, FUNED, LAFEPE entre outros) e privados. Mesmo que se considere que os laboratórios públicos não podem exportar sua produção(98), com exceção do Far-Manguinhos ${ }^{(99)}$, este sistema poderia ser bastante favorável ao desenvolvimento da indústria privada de medicamentos genéricos, ainda pouco desenvolvida. É assim que o Brasil busca conquistar os mercados africanos lusófonos.

Diante disso, é difícil compreender o porquê do país não regulamentar este instrumento jurídico em prol de um melhor acesso a medicamentos, uma vez que faz uso das flexibilidades clássicas do direito de patentes. Existem várias razões que explicam esse paradoxo brasileiro.

Em princípio, não se pode subestimar as pressões exercidas pelos Estados Unidos sobre o Brasil, que nem sempre pode agir de acordo com sua conveniência. Destaque-se como o país, submisso à retaliações comerciais norte-americanas, não teve outra escolha a não ser reconhecer, de maneira precoce, a patenteabilidade dos produtos farmacêuticos.

De outro ponto de vista, vale lembrar que mesmo que os Estados Unidos tivessem retirado a reclamação contra o Brasil, feita junto ao Órgão de Solução de Diferenças, da OMC, em 2001, afirmando que certas disposições da legislação brasileira de propriedade industrial de 1996, relativas ao

(97) Cf. BERMUDEZ, J.; EPSTEJN, R.; OLIVEIRA, M.; HASENCLEVER, L. op. cit., p. 88. CORIAT, B.; DUMOULIN, J.; FLORY, Y.-A.; BARNETT, T.; SOUTEYRAND, Y.; MOATTI, J.-P. Patents, generic drugs and the markets for antiretrovirals. In: MOATTI, J.-P.; CORIAT, B.; SOUTEYRAND, Y; BARNETT, T.; DUMOULIN, J.; FLORY, Y.-A. Economics of AIDS and access to HIV/AIDS care in developing countries. Issues and challenges. ANRS, 2003. p. 32. (Collection Sciences Sociales et Sida).

(98) Em nome de seu caráter público, os laboratórios oficiais produzem apenas medicamentos solicitados pelo Ministério da Saúde. Os laboratórios não têm a vocação para desenvolver suas próprias atividades produtivas, sem o comando do governo; assim, o excedente de produção é bastante raro.

(99) Far-Manguinhos foi autorizado pela Lei $\mathrm{n} .10 .858$, de 13 de abril de 2004, a exportar eventuais sobras de produção para países com os quais o Brasil mantém acordos de cooperação. 
licenciamento compulsório, estariam em desacordo com o TRIPS ${ }^{(100)}$, o Brasil aceitou "negociar, com o governos dos Estados Unidos, a concessão de licença compulsória para patentes de empresas norte-americanas, mesmo em situações nas quais julgue necessário aplicar o art. 68”(101). Pode-se então imaginar que a não regulamentação da decisão de 30 de agosto é objeto de negociações com os Estados Unidos e faz parte de uma estratégia global de negociações comerciais.

Em seguida, à luz das negociações realizadas dentro da indústria de genéricos, pode-se constatar o desconhecimento por parte do setor farmacêutico da existência da decisão de 30 de agosto e das possibilidades de desenvolvimento que ela oferece. Resta apenas, então, encorajar os fabricantes de genéricos brasileiros a se unir e se inteirar dos instrumentos jurídicos disponíveis no direito internacional de patentes para a promoção do acesso a medicamentos, dirigidos aos países mais pobres. Também vale chamar a atenção do governo para que sejam consideradas as oportunidades industriais previstas neste mecanismo.

\section{CONCLUSÃO}

O Brasil, adaptando sua legislação de propriedade industrial às obrigações internacionais definidas pelo Acordo TRIPS, desejou conciliar o acesso a medicamentos e a patenteabilidade dos produtos farmacêuticos. Porém, o país adotou estratégias paradoxais, explorando ao máximo as flexibilidades tradicionais disponíveis no direito de patentes - e indo além com a criação de mecanismos jurídicos inovadores, como a anuência prévia - , mas não se beneficiando das flexibilidades originais do Acordo TRIPS, por vezes, ultrapassando até mesmo as exigências do Direito Comercial Internacional.

\section{REFERÊNCIAS BIBLIOGRÁFICAS}

AGIF. Lignes directrices pour l'examen des demandes de brevet dans les domaines biotechnologiques et pharmaceutiques déposées après le 31 décembre 1994. Disponivel em: <http://www.agif.com.br/download/INPI-diretrizes\%20para\% 20exame.doc>.

(100) Os Estados Unidos contestam a validade do art. 68 da legislação brasileira que prevê que uma patente poderá ser objeto de licenciamento compulsório em caso da invenção não ser "explorada" em território brasileiro, sendo que a não exploração é definida no Brasil como a não fabricação ou a fabricação incompleta do produto ou a não utilização ou o uso incompleto de um processo. Os norte-americanos acreditam que tal definição é incompatível com as obrigações dos arts. 27 (objeto patenteável) e 28 (direitos conferidos por uma patente) do Acordo TRIPS e do art. III (princípio do tratamento nacional) do GATT de 1994.

(101) Cf. o documento WT/DS199/4, de 19 de julho de 2001 no site da OMC. 
ANVISA. Esclarecimentos sobre pedidos de patentes dos produtos e processos farmacêuticos. Disponível em: <http://www.anvisa.gov.br/divulga/alertas/ 2004/250804.htm>.

AOL. <http://noticias.aol.com.br/negocios/industria/2004/06/0009.adp>.

BARBOSA, D. Uma introdução à propriedade intelectual. 2. ed. Rio de Janeiro: Lumen Juris, 2003.

BASSO, M. A Anvisa e a concessão de patentes farmacêuticas. Publié le 18 octobre 2004 sur le site: <www.tecpar.br>.

BERMUDEZ, J.; Auxiliadora Oliveira M.; CHAVES, G. Costa. O acordo TRIPS da OMC e os desafios para a saúde pública. In: Acceso a medicamentos: derecho fundamental. Papel del Estado. Rio de Janeiro: Fiocruz/ENSP, 2004.

BERMUDEZ, J.; EPSTEJN, R.; OLIVEIRA, M.; HASENCLEVER, L. The WTO TRIPS Agreement and Patent Protection in Brazil: recent changes and implications for local production and access to Medicines. Rio de Janeiro: WHO/ PAHO/ENSP, Apr. 2000.

BERNARDES, Marques M. Saúde pública, ética e mercado no entreato de dois séculos. São Paulo: Brasiliense, 2005.

CORIAT, B.; DUMOULIN, J.; FLORY, Y.-A.; BARNETT, T.; SOUTEYRAND, Y.; MOATTI, J.-P. Patents, generic drugs and the markets for antiretrovirals. In: MOATTI, J.-P.; CORIAT, B.; SOUTEYRAND, Y. BARNETT, T.; DUMOULIN, J.; FLORY, Y.-A. Economics of AIDS and access to HIVIAIDS care in developing countries. Issues and challenges. ANRS, 2003. (Collection Sciences Sociales et Sida).

CORREA, Carlos. El Acuerdo TRIPS. Buenos Aires: Ed. Ciudad Argentina, 1996.

CORREA, Carlos. Intégration des considérations de santé publique dans la législation en matière de brevets dans les pays en développement. South Centre, nov. 2001.

ESTADÃO. <http://www.estadao.com.br/nacional/noticias/2005/jun/29/ 161.htm>.

FOYER, J.; VIVANT, M. Le droit des brevets. Paris: Thémis, 1990.

HERMITTE M.-A. Bioéthique et brevets dans le droit du commerce international: la construction d'un nouveau contrat social. In: MALJEAN-DUBOIS, S. (Dir.) La communauté internationale et les enjeux bioéthiques. Paris: Pedone, 2005.

INSTITUTO DANNEMANN SIEMSEN DE ESTUDOS DE PROPRIEDADE INTELECTUAL. Comentários à Lei da Propriedade Industrial. Rio de Janeiro: Renovar, 2005. 
MINISTÉRIO DA SAÚDE. <http://www.aids.gov.br/data/Pages/LUMIS13F4BF21 PTBRIE.htm>.

MONDIALISATION et accès aux médicaments: perspectives sur l'accord ADPIC de l'OMC. Programme d'Action pour les Médicaments Essentiels, 1999. (Série Economie de la Santé et Médicaments, n. 7).

POLLAUD-DULLIAN, F. Droit de la propriété industrielle. Paris: Montchrestien, 1999. (Collection Domat droit privé).

RAVILLARD, P. La décision du 30 août 2003 sur l'accès aux médicaments: une étape historique dans le processus des négociations de l'OMC. Propriétés Intellectuelles, n. 10, janv. 2004.

RODRIGUES, E. Beas. Anuência prévia: integração do direito à saúde aos direitos de propriedade intelectual. out. 2005.

TACHINARDI, M. A guerra das patentes: o conflito Brasil \& EUA sobre Propriedade Intelectual. Rio de Janeiro: Paz e Terra, 1993.

TEULON, F. Problèmes économiques contemporains: les pays en développement. Les Fondamentaux, Hachette, 1999.

VIALA, G.; BURTIN, J.-F. La libre circulation des médicaments et ses limites, au travers de la jurisprudence de la Cour de justice des Communautés européennes. RD San. Soc. V. 34, n. 1, p. 81, janv./mars 1998.

WORLD TRADE ORGANIZATION. <http://www.wto.org/french/docs_f/legal_f/ 27-trips.pdf>.

\section{VERSÃO EM FRANCÊS}

\section{Droit de Propriété Industrielle et L’aCcès AuX Médicaments Contre le Sida au Brésil}

Amélie Robine ${ }^{(\star)}$

\section{INTRODUCTION}

Les droits de propriété industrielle, et partant le droit des brevets, sont régis au niveau international par l'accord sur les ADPIC (Aspects des Droits

(*) Doctorante en Droit à I 'Université de Paris I Panthéon-Sorbonne. 
de Propriété Intellectuelle qui touchent au Commerce), ${ }^{(1)}$ entré en vigueur le 1er janvier 1995. L'accord impose aux États membres des obligations minimales dans les différents domaines de la propriété intellectuelle. En ce qui concerne plus particulièrement le droit des brevets, l'accord oblige les Etats membres à reconnaître la brevetabilité des produits \& procédés pharmaceutiques ${ }^{(2)}$. Cette obligation est justifiée par l'idée que les brevets dans le domaine pharmaceutique sont nécessaires pour encourager la recherche et le développement de nouveaux médicaments, en tant qu'ils offrent, à travers un monopole d'exploitation de 20 ans $^{(3)}$ à leurs titulaires, un retour sur investissement des dépenses engagées pour la recherche de nouvelles molécules. Les brevets pharmaceutiques - au vu des monopoles qu'ils confèrent - constituent dès lors une exception au principe de libre concurrence et riment en général avec prix élevés ${ }^{(4)}$. Or, si les coûts des médicaments brevetés sont pris en charge par des systèmes de sécurité sociale dans les pays industrialisés, ces coûts sont supportés directement par les malades dans les pays en développement, ce qui pose en pratique des problèmes d'accès aux médicaments pour les populations pauvres. C'est donc pour remédier à cette problématique "d'accès aux médicaments", que les pays en développement adoptaient traditionnellement des législations excluant les médicaments de la brevetabilité: ces législations permettaient aux plus avancés d'entre eux de fabriquer localement des copies bon marché des médicaments brevetés.

L'accord sur les ADPIC, afin de sauvegarder la concurrence d'une part, la santé publique d'autre part, a retenu les flexibilités "classiques" relatives à l'exercice du droit de brevet: licences obligatoires ${ }^{(5)}$, importations parallèles ${ }^{(6)}$, ou encore faculté pour un État membre de prendre les mesures nécessaires à la sauvegarde de la santé publique, dans la mesure où elles ne constituent pas un obstacle au commerce ${ }^{(7)}$, Ces flexibilités se sont toutefois avérées trop réduites au regard des exigences sanitaires, et plus particulièrement dans le contexte de la pandémie de sida qui touche les pays pauvres de façon drastique. C'est donc pour tenter de résoudre les problèmes de santé publique de ces derniers que des négociations entamées sous l'égide de l'Organisation Mondiale du Commerce (OMC) à Doha en 2001, ont abouti à

(1) L'accord dépend de l'architecture générale de l'Organisation Mondiale du Commerce et peut être consulté sur le site: WORLD TRADE ORGANIZATION. <http://www.wto.org/french/docs_f/legal_f/ 27-trips.pdf>.

(2) L'article 27 de l'accord sur les ADPIC dispose en effet qu' "un brevet pourra être obtenu pour toute invention, de produit ou de procédé, dans tous les domaines technologiques, à condition qu'elle soit nouvelle, qu'elle implique une activité inventive et qu'elle soit susceptible d'application industrielle".

(3) Cf. Article 33 de l'accord sur les ADPIC.

(4) Cf. par exemple, B. Remiche et H. Desterbecq, "Les brevets pharmaceutiques dans les accords

du GATT: l'enjeu ?", RIDE, 1996, p. 13.

(5) Article 31 de l'accord sur les ADPIC.

(6) Article 6 de l'accord sur les ADPIC.

(7) Article 8 de l'accord sur les ADPIC. 
une décision originale: la décision du 30 août 2003. Cette dernière entend résoudre les problèmes d'accès aux médicaments dans les pays qui ne disposent pas de capacité de production pharmaceutique locale ou qui disposent de capacité industrielle insuffisante pour couvrir les besoins de leurs populations; à côté des flexibilités "classiques" du droit des brevets, elle introduit des flexibilités originales.

Le Brésil fait partie des pays émergents ${ }^{(8)}$, caractérisé par de grandes inégalités économiques et sociales. II fait figure d'exemple au niveau mondial, puisqu'il est parvenu à stopper la propagation de l'épidémie de sida $^{(9)}$, alors que les experts des organisations internationales avaient autrefois prédit une "africanisation" du pays. Cette réussite est à mettre sur le compte d'un programme national hors pair de lutte contre le sida et les infections sexuellement transmissibles, sans que cela l'ait empêché d'adapter sa législation en matière de propriété industrielle aux standards internationaux, tels qu'élaborés par l'accord sur les ADPIC. Or le Brésil avait longtemps développé une industrie pharmaceutique de copie, car sa législation excluait les produits pharmaceutiques de la brevetabilité.

II semble donc pertinent d'étudier comment le Brésil a marié les exigences sanitaires à l'intégration des contraintes posées par le droit international des brevets et plus particulièrement à l'obligation de délivrer des brevets dans le domaine pharmaceutique. Dans quelle mesure sa loi de propriété industrielle parvient-elle à articuler d'un côté, les exigences du commerce mondial, de l'autre, l'impératif d'accès aux médicaments contre le VIH/SIDA? L'analyse mène à un constat mitigé: si certaines dispositions, au demeurant fort originales pour la plupart, parviennent à opérer cette articulation (I), d'autres sont loin d'être à la hauteur des enjeux (II).

\section{LES DISPOSITIONS DE LA LÉGISLATION BRÉSILIENNE EN FAVEUR DE L'ACCĖS AUX MÉDICAMENTS}

Afin de se mettre en conformité avec les dispositions de l'accord sur les ADPIC, le Brésil s'est doté d'une nouvelle législation en matière de propriété

\footnotetext{
(8) Les pays émergents ou les Nouveaux Pays Industrialisés (NPI) sont des pays qui connaissent un rythme de croissance soutenu et qui sont désormais des producteurs importants de biens manufacturés. Les organisations internationales retiennent trois critères pour les définir:

- forte croissance économique et accroissement soutenu de l'emploi dans le secteur industriel;

- revenu moyen élevé par rapport aux autres pays en développement et réduction des écarts de revenu avec les pays développés;

- orientation de l'économie vers l'extérieur et accroissement du poids des exportations de produits manufacturés dans le total des exportations.

Cf. TEULON, F. Problèmes économiques contemporains: les pays en développement. Les Fondamentaux, Hachette, 1999. p. 151.

(9) Le Brésil compte près de 593.000 personnes contaminées en 2004. Le taux de prévalence en 2005 a été estimé à $0.7 \%$ (en France, le taux de prévalence est estimé à $0.4 \%$ ).

Source: MINISTÉRIO DA SAÚDE. <http://www.aids.gov.br/data/Pages/LUMIS13F4BF21PTBRIE.htm>.
} 
industrielle. II s'agit de la loi n. 9.279 du 14 mai 1996 réglementant les droits et obligations relatives à la propriété industrielle ${ }^{(10)}$. Cette nouvelle législation revêt un caractère original dans la mesure où elle utilise la technique classique du droit des brevets dans une optique de santé publique $(A)$ et elle permet à des institutions publiques de réguler l'octroi de brevets pharmaceutiques d'une façon qui satisfait l'accès aux médicaments (B).

\section{A. L'utilisation à des fins de santé publique de la technique classique du droit des brevets}

La loi de 1996 a intégré les critères et les exclusions classiques de brevetabilité (1), ainsi que le mécanisme de licence obligatoire (2) dans une optique largement sanitaire.

\section{Les critères \& exclusions classiques de brevetabilité}

Alors que la loi du 21 décembre $1971,{ }^{(11)}$ ne prévoyait que deux critères de brevetabilité (la nouveauté et l'applicabilité industrielle de l'invention), l'article 8 de la loi de $1996^{(12)}$ reprend les trois critères énoncés dans la législation internationale: "un brevet pourra être obtenu pour toute invention de produit ou de procédé, dans tous les domaines technologiques, à condition qu'elle soit nouvelle, qu'elle implique une activité inventive et qu'elle soit susceptible d'application industrielle". ${ }^{(13)}$

Ce faisant, le nouveau texte fait entrer les produits \& procédés pharmaceutiques dans le champ de la brevetabilité à compter du 14 mai 1997, date d'entrée en vigueur de la loi(14).

Afin de limiter autant que faire se peut le champ de la brevetabilité, l'article 10 de la loi de 1996 reprend les exclusions prévues par l'accord sur les ADPIC: les découvertes, théories scientifiques et méthodes mathématiques, les conceptions purement abstraites, les schémas, plans, méthodes commerciales, les œuvres littéraires, les programmes d'ordinateurs en tant que tels, les règles de jeux, les techniques et méthodes opératoires ou chirurgicales, ainsi que les méthodes thérapeutiques ou diagnostiques appliquées

(10) DOU du 15 mai 1996.

(11) Loi du 21 décembre 1971 instituant un code de propriété industrielle, DOU du 31 décembre 1971.

(12) Article 8: "E patenteavel a invenção que atenda aos requisitos de novidade, atividade inventiva e aplicação industrial".

(13) Article 27 de l'accord sur les ADPIC.

(14) Des dispositions ont toutefois été prévues pour les demandes de brevet déposées entre le $1^{\text {er }}$ janvier 1995 et le 14 mai 1997, ainsi que pour les pipelines de brevets. Nous reviendrons ultérieurement sur ces dispositions. 
au corps humain ou animal, tout ou partie des êtres vivants naturels et matériaux biologiques rencontrés dans la nature etc. ... (15)

Au regard de la question de l'accès aux médicaments, ces changements engendrent plusieurs conséquences: d'une part, aucun médicament commercialisé dans le monde avant le 14 mai 1997 ne pourra être breveté au Brésil, la loi n'ayant pas d'effet rétroactif. Ainsi, les molécules de base utilisées dans le traitement du VIH/SIDA, comme l'AZT, la Névirapine ou l'Indivir pourront toujours être fabriquées en toute légalité par les industries génériques brésiliennes. En revanche, pour ce qui concerne les médicaments brevetés au Brésil après cette date, ils ne pourront être fournis par les laboratoires brésiliens qu'à la condition que les multinationales détentrices des brevets sur lesdits médicaments leur aient octroyé une licence volontaire - ce qui est très rare dans la pratique - ou que le gouvernement brésilien ait émis une licence obligatoire autorisant ses laboratoires nationaux à produire le ou les médicaments brevetés sans le consentement du titulaire du brevet - ce qui suppose la réunion de conditions et circonstances bien précises (en cas d'urgence sanitaire par exemple). Dans une très large majorité des cas, les traitements de dernière génération seront donc fournis par les multinationales à des coûts plus élevés que s'ils avaient été fournis par des génériqueurs, ce qui met en péril le programme brésilien d'accès aux médicaments contre le SIDA.

A côté des critères et exclusions classiques de brevetabilité, le Brésil a intégré pleinement une des flexibilités prévues par l'accord sur les ADPIC et la déclaration de Doha: le mécanisme de licence obligatoire, qui favorise l'accès aux médicaments.

\section{L'intégration du mécanisme de licence obligatoire}

La licence obligatoire est une flexibilité classique du droit des brevets, en vertu de laquelle, dans certaines hypothèses, un tiers peut se voir conférer

(15) Artigo 10: "Não se considera invenção nem modelo de utilidade:

I - descobertas, teorias científicas e métodos matemáticos;

II - concepções puramente abstratas;

III - esquemas, planos, princípios ou métodos comerciais, contábeis, financeiros, educativos, publicitários, de sorteio e de fiscalização;

IV - as obras literárias, arquitetônicas, artísticas e científicas ou qualquer criação estética;

$\mathrm{V}$ - programas de computador em si;

VI - apresentação de informações;

VII - regras de jogo;

VIII - técnicas e métodos operatórios ou cirúrgicos, bem como métodos terapêuticos ou de diagnóstico, para aplicação no corpo humano ou animal; e

IX - o todo ou parte de seres vivos naturais e materiais biológicos encontrados na natureza, ou ainda que dela isolados, inclusive o genoma ou germoplasma de qualquer ser vivo natural e os processos biológicos naturais". 
une licence d'exploitation de l'invention, contrairement à la volonté du titulaire du brevet. Véritable "brèche légale"(16) dans le monopole, la restriction au droit exclusif est fondée sur des considérations d'équité: le monopole doit s'effacer devant l'intérêt général, ne laissant au breveté qu'un droit à redevance. Autorisée à l'article 31 de l'accord sur les ADPIC $^{(17)}$, la plupart des États ont organisé ce régime d'exception classique au sein de leurs législations. Et si le Brésil ne déroge pas à cette règle (a), il a toutefois utilisé la stratégie de licence obligatoire d'une manière tout à fait originale (b).

\section{a. Le principe de la licence obligatoire comme instrument d'accès aux médicaments}

L'article 31 de l'accord sur les ADPIC laisse les États membres libres de déterminer les motifs pour lesquels une licence obligatoire peut être accordée. II établit toutefois un certain nombre de conditions à respecter. C'est ainsi que le demandeur d'une licence obligatoire aura dû s'être efforcé d'obtenir au préalable une licence volontaire du titulaire du brevet de l'invention (sauf dans des situations d'urgence nationale, d'autres circonstances d'extrême urgence ou en cas d'utilisation publique à des fins non commerciale), que la portée et la durée de la licence obligatoire devront être limitées, que la licence sera non exclusive, incessible et sera autorisée principalement pour l'approvisionnement du marché intérieur et que le détenteur du droit devra recevoir une rémunération adéquate.

En pratique, la licence obligatoire est délivrée soit par une autorité judiciaire, soit par une autorité publique. Les motifs de licence les plus communs sont les suivants: licence obligatoire pour défaut d'exploitation de l'invention, licence de dépendance (qui recouvre l'hypothèse dans laquelle un inventeur invente un perfectionnement à une invention brevetée par exemple), licence dans l'intérêt de la santé publique ${ }^{(18),}$ licence dans l'intérêt public, licence dans l'intérêt de l'économie nationale, licence dans l'intérêt de la défense nationale.

Dans la problématique de l'accès aux médicaments, la licence obligatoire revêt un intérêt certain ${ }^{(19)}$ puisqu'en cas de pandémie, à l'instar du sida ou de la grippe aviaire, elle peut être utilisée pour fabriquer des génériques,

(16) POLLAUD-DULLIAN, F. Droit de la propriété industrielle. Paris: Montchrestien, 1999. p. 233. (Collection Domat droit privé).

(17) L'article 31 de l'accord sur les ADPIC parle des "autres utilisations sans autorisation du détenteur du droit".

(18) Cf. par exemple, l'article L.613-16 du code français de la propriété intellectuelle qui dispose que, si l'intérêt de la santé publique l'exige, le Ministre de la santé peut demander au Ministre chargé de la propriété industrielle de soumettre à un régime de licence d'office un brevet de médicament ou un brevet couvrant un procédé d'obtention ou un produit nécessaire à l'obtention de médicaments. (19) Cf. l'exemple des États-Unis qui avaient menacé Bayer d'une licence obligatoire pour son Cipro dans le cadre des attaques à la maladie du charbon, suite aux attentats du 11 septembre 2001. 
en passant outre les droits du titulaire du brevet. L'intérêt public prévaut dans ce cas sur l'intérêt individuel. Cette flexibilité a été réaffirmée par la Déclaration de Doha sur l'accord sur les ADPIC et la santé publique du 14 novembre $2001^{(20)}$ qui dispose: "nous reconnaissons la gravité des problèmes de santé publique qui touchent de nombreux pays en développement et pays les moins avancés, en particulier ceux qui résultent du VIH/SIDA, de la tuberculose, du paludisme et d'autres épidémies. [...] Nous convenons que l'accord sur les ADPIC n'empêche pas et ne devrait pas empêcher les Membres de prendre des mesures pour protéger la santé publique. [...] Chaque Membre a le droit d'accorder des licences obligatoires et la liberté de déterminer les motifs pour lesquels de telles licences sont accordées".

La licence obligatoire peut alors être utilisée comme un instrument d'accès aux médicaments en tant qu'elle autorise un ou des licenciés à fabriquer localement, sans l'autorisation du titulaire du brevet, les médicaments brevetés à des coûts en général inférieurs aux médicaments brevetés et qu'elle permet de multiplier les sources d'approvisionnement en cas de pandémie. Mais elle peut aussi être utilisée comme un instrument de politique industrielle; en effet, elle peut être considérée comme un moyen, pour un pays émergent ou en développement, d'acquérir des connaissances scientifiques et technologiques pour développer une industrie pharmaceutique locale.

En vertu de la section III de la loi de 1996, une licence obligatoire peut être octroyée au Brésil pour abus de droit du titulaire du brevet, pour abus de pouvoir économique, défaut d'exploitation de l'invention sur le territoire national, défaut de commercialisation suffisante (ou qui ne satisfait pas aux besoins du marché), pour brevet de dépendance, en cas d'urgence nationale ou d'intérêt public ${ }^{(21)}$. Si le champ d'application de la licence obligatoire peut

(20) Document n. WT/MIN(01)/DEC/2, publié sur le site de l'OMC: WORLD TRADE ORGANIZATION. <http://docsonline.wto.org/DDFDocuments/u/WT/Min01/DEC2.doc>.

(21) Seção III: "Da Licença Compulsória

Art. 68. O titular ficará sujeito a ter a patente licenciada compulsoriamente se exercer os direitos dela decorrentes de forma abusiva, ou por meio dela praticar abuso de poder econômico, comprovado nos termos da lei, por decisão administrativa ou judicial.

$\S 1^{\circ}$ Ensejam, igualmente, licença compulsória:

I - a não exploração do objeto da patente no território brasileiro por falta de fabricação ou fabricação incompleta do produto, ou, ainda, a falta de uso integral do processo patenteado, ressalvados os casos de inviabilidade econômica, quando será admitida a importação; ou II - a comercialização que não satisfizer às necessidades do mercado [...].

Art. 70. A licença compulsória será ainda concedida quando, cumulativamente, se verificarem as seguintes hipóteses:

I - ficar caracterizada situação de dependência de uma patente em relação a outra;

II - o objeto da patente dependente constituir substancial progresso técnico em relação à patente anterior; e

III - o titular não realizar acordo com o titular da patente dependente para exploração da patente anterior [...]. 
paraître large, elle est toutefois soumise à des conditions restrictives: une licence ne peut être demandée que par une partie ayant un intérêt légitime et dotée des capacités techniques ou économiques indispensables à une exploitation effective de l'objet breveté ; une licence obligatoire ne peut être demandée qu'à l'expiration d'un délai de trois ans à compter de la délivrance du brevet (sauf en cas d'urgence nationale, d'intérêt public ou pour brevet de dépendance).

Notons que le Brésil présente la particularité(22) d'avoir défini les notions d'urgence nationale et d'intérêt public dans un décret de 1999.(23). L'urgence nationale s'entend comme un "danger public imminent"(24) et l'intérêt public comme "les faits en rapport, entre autres, à la santé publique, à la nutrition, à la protection de l'environnement, ainsi que ceux de première importance au regard du développement technologique ou socio-économique du pays"(25).

Mais l'originalité du Brésil tient surtout dans l'utilisation de la licence obligatoire comme instrument de négociation des prix des médicaments. Plus exactement, le Brésil a usé à plusieurs reprises de la menace d'octroyer une licence obligatoire pour obtenir des réductions de prix significatives des antirétroviraux brevetés.

\section{b. L'utilisation brésilienne de la menace de l'utilisation de la licence obligatoire}

Le Brésil a usé de la "menace" de licence obligatoire comme d'une véritable stratégie pour négocier des baisses de prix des médicaments protégés par brevet des multinationales dans le domaine du VIH/SIDA. Le seul fait d'annoncer qu'il allait émettre une licence obligatoire suffisait à entamer les négociations des prix des médicaments de dernière génération - très onéreux - avec les firmes pharmaceutiques multinationales.

Le Brésil a mis en œuvre cette stratégie pour la première fois en 2001. II s'agissait de négocier le prix de quatre ARVs de nouvelle génération (Efavirenz, Indinavir, Nelfinavir et Lopinavir/r) avec les laboratoires détenteurs des brevets sur ces molécules, à savoir Merck \& Co, Roche et Abbott.

Art. 71. Nos casos de emergência nacional ou interesse público, declarados em ato do Poder Executivo Federal, desde que o titular da patente ou seu licenciado não atenda a essa necessidade, poderá ser concedida, de ofício, licença compulsória, temporária e não exclusiva, para a exploração da patente, sem prejuízo dos direitos do respectivo titular."

(22) L'accord sur les ADPIC ne définit pas ces notions.

(23) Décret n. 3.201 du 6 octobre 1999, publié au DOU du 7 octobre 1999.

(24) Artigo $2^{\circ}, \S 1^{\circ}$ "Entende-se por emergência nacional o iminente perigo publico, ainda que apenas em parte do territorio nacional".

(25) Artigo $2^{\circ}, \S 2^{\circ}$ "Consideram-se de interesse público os fatos relacionados, dentre outros, à saude publica, à nutrição, à defesa do meio ambiente, bem como aqueles de primordial importância para o desenvolvimento tecnológico ou socio-econômico (sic) do País". 
S'appuyant sur la capacité de Far-Manguinhos à reproduire par la technique de l'ingénierie inverse les médicaments en cause à des coûts très compétitifs, le gouvernement brésilien menaçait les multinationales d'émettre une licence obligatoire. En effet, les prix prohibitifs de ces molécules risquaient de limiter le nombre de malades pris en charge par le programme de lutte contre le SIDA, et d'en compromettre à terme la viabilité(26). II obtint des réductions de prix allant de 40 à $65 \%$ et un accord de principe pour le transfert de technologie de l'Indinavir (licence volontaire) fut signé entre Merck \& Co et Far-Manguinhos ${ }^{(27)}$. Ce dernier point est important car il montre la synergie entre la politique des prix et la politique industrielle.

Le dernier accord en date a été signé le 10 octobre 2005 avec Abbott pour le Kaletra (Lopinavir/r). Cette fois, le gouvernement brésilien est allé plus loin dans sa stratégie d'utilisation de la menace de licence obligatoire, puisque le Ministre de la santé Humberto Costa avait déclaré les médicaments résultant de l'association des principes actifs du Lopinavir et du Ritonavir d'intérêt public par un arrêté ministériel du 24 juin $2005^{(28)}$. Pour le Ministre de la santé en effet, la viabilité du programme de lutte contre le SIDA était remise en cause par le prix d'achat du Kaletra, compte tenu de l'augmentation du nombre de personnes devant être prises en charge par le programme ${ }^{(29)}$. L'État devant garantir le droit à la santé pour tous au titre de l'article 196 de la Constitution brésilienne et la prise en charge gratuite et universelle des séropositifs et sidéens en vertu de la loi du 13 novembre 1996, il se devait d'assurer la pérennité de son programme de lutte contre le sida, ce qui passait par une réduction significative du prix du Kaletra. Soutenu par la société civile internationale et par l'OMS ${ }^{(30)}$, le gouvernement brésilien annonçait le 8 juillet 2005 qu'un accord avait été trouvé avec Abbott ${ }^{(31)}$. Le même jour, un remaniement ministériel intervint et le nouveau Ministre de la santé José Saraiva Felipe fit part de son intention sinon d'émettre une licence obligatoire, de poursuivre les négociations avec Abbott, arguant du fait qu'aucun accord écrit n'avait été finalisé(32). Le 11 août 2005, le Conseil National de la Santé - organe rattaché au Ministère de la santé - approuva à l'unanimité une résolutionn ${ }^{(33)}$ recommandant au Ministre de la santé:

(26) BERMUDEZ, J., Auxiliadora Oliveira M. e CHAVES, G. Costa. O acordo TRIPS da OMC e os desafios para a saúde pública. In: Acceso a medicamentos: derecho fundamental. Papel del Estado. Rio de Janeiro: Fiocruz/ENSP, 2004. p. 76.

(27) La licence volontaire est toujours en cours de négociation à l'heure actuelle.

(28) Portaria n. 985, publiée au DOU du 27 juin 2005.

(29) Artigo 1: "Declara, para fins de sustentabilitade social do programa brasileiro de combate à AIDS, interesse público relativamente aos medicamentos advindos da associação dos princípios ativos Lopinavir e Ritonavir, com vistas à composição do rol dos inibidores de protease que devem compor o arsenal terapêutico para o tratamento da infecção por HIV/AIDS no Brasil".

(30) "WHO congratulates Brazil for the breaking of the patent of the aids medicine", publie le 29 juin 2005 sur le site: ESTADÃO. <http://www.estadao.com.br/nacional/noticias/2005/jun/29/161.htm>.

(31) Cf. le Monde du 12 juillet 2005.

(32) "Brazil's corruption scandal may deal a blow to intellectual property rights", The Economist, July 21 st 2005.

(33) Resolução CNS n. X. 
- l'arrêt des négociations,

- l'émission immédiate d'une licence obligatoire non seulement pour le Lopinavir/r, mais aussi pour l'Efavirenz, le Tenofovir et pour tout autre médicament breveté utilisé dans le traitement du VIH/SIDA dont les coûts d'achat étaient excessifs,

- et la fabrication locale des médicaments en cause.

Le gouvernement brésilien a toutefois préféré poursuivre les négociations qui ont mené à la signature d'un contrat en octobre 2005. Au terme de ce contrat, des réductions de prix significatives par unité ont été consenties pour deux anciennes formulations du Kaletra (capsules et comprimés). Concernant la nouvelle formulation, une réduction de prix a été accordée par unité pour une quantité d'achat prédéfinie ( 2.830 .680 capsules). Et Abbott s'est engagée à fournir gratuitement le Kaletra dans sa formulation orale à usage pédiatrique. La fourniture de Kaletra au gouvernement brésilien est en revanche expressément limitée à l'usage des patients brésiliens et ne peut donc être exportée. En outre, le gouvernement brésilien s'est engagé quant à lui à respecter "intégralement" les droits de propriété intellectuelle relatifs aux principes actifs du Lopinavir et du Ritonavir. Le contrat stipule par ailleurs qu'Abbott ne fournira aucune assistance de fabrication, ce qui exclut tout transfert de technologie pendant la durée du contrat, à savoir jusqu'au 31 décembre $2011^{(34)}$.

Le Brésil a donc cherché à tiré parti des exigences et des flexibilités classiques du droit des brevets d'une façon qui promeut l'accès aux médicaments. II a été plus avant dans cette démarche en offrant à des institutions publiques des modalités d'interventions originales dans l'octroi de brevets pharmaceutiques.

\section{B. L'intervention originale d'institutions publiques dans l'octroi de brevets pharmaceutiques}

La loi de 1996 créé deux mécanismes intéressants en tant qu'ils limitent l'octroi de brevets dans le domaine pharmaceutique: tout d'abord, elle soumet à l'Agence Nationale de Vigilance Sanitaire (ANVISA) l'octroi de titres de brevets (a); ensuite, elle offre à des institutions publiques à l'instar du

(34) Notons que ce contrat a été vivement décrié par les ONG brésiliennes de lutte contre le sida. Elles dénonçaient d'une part, le caractère fixe des réductions de prix consenties par le laboratoire américain qui va à l'encontre de toute logique économique et d'autre part, la clause expresse excluant tout transfert de technologie du Kaletra qui maintient le Brésil sous la dépendance technologique d'Abbott. Selon les ONG, ce contrat ne garantit donc ni la pérennité financière du programme national de lutte contre le sida, ni la prise en charge de nouveaux malades. Et c'est pour pousser le gouvernement à émettre une licence obligatoire pour le Kaletra, qu'elles ont intenté le 1er décembre 2005 (journée mondiale de lutte contre le sida), une action civile publique à son encontre. 
laboratoire public Far-Manguinhos le droit de participer au processus d'examen de la demande de brevet (b).

\section{L'autorisation de l'ANVISA préalable à l'octroi de titres de brevets}

Le 14 décembre $1999^{(35)}$, le Président Cardoso introduit un nouvel article dans la loi de 1996: l'article 229-C qui établit un dispositif inédit. ${ }^{(36)}$. II soumet en effet la délivrance des brevets pharmaceutiques à l'anuência prévia de l'ANVISA ${ }^{(37)}$. La justification est la suivante: I'Institut National de la Propriété Industrielle (INPI) n'ayant pas d'expertise technique dans le domaine pharmaceutique, on ne peut soumettre la délivrance des brevets dans un secteur aussi sensible en tant qu'il touche la santé publique, à un organe incompétent. II semble donc opportun de confier l'examen des demandes de brevets de médicaments non seulement à I'INPI, en application de l'article 240 de la loi de 1996, mais aussi à l'organisme chargé par ailleurs d'autoriser leur mise sur le marché(38). L'autorisation préalable de l'ANVISA constitue dès lors un stade supplémentaire dans le processus d'examen de la demande de brevet. Ce mécanisme juridique, bien que fort controversé tant au vu du procédé législatif utilisé( ${ }^{(39)}$ que de sa compatibilité avec les règles de droit international(40), a été entériné par la loi du 14 février $2001^{(41)}$.

En adoptant un mécanisme sui generis d'analyse des demandes de brevets pour les produits et procédés pharmaceutiques, le Brésil affiche très clairement sa volonté de prendre en compte les enjeux de santé publique au sein du droit des brevets, préoccupation en réalité constante au sein de la législation brésilienne.

(35) Mesure Provisoire n. 2.006 publiée au DOU du 15 décembre 1999.

(36) En effet, ce mécanisme est inexistant dans les législations des autres pays du monde. Source: INSTITUTO DANNEMANN SIEMSEN DE ESTUDOS DE PROPRIEDADE INTELECTUAL. Comentários à Lei da Propriedade Industrial. Rio de Janeiro: Renovar, 2005. p. 492.

(37) Artigo 229-C. "A concessão de patentes para produtos e processos farmacêuticos dependerá da prévia anuência da Agência Nacional de Vigilância Sanitária (ANVISA)".

(38) Cf. BASSO, M. A Anvisa e a concessão de patentes farmacêuticas. Publié le 18 octobre 2004 sur le site: <www.tecpar.br>.

(39) L'article 62 de la Constitution brésilienne de 1988 dispose que le Président de la République peut adopter des mesures provisoires en cas d'importance particulière ou d'urgence. En l'espèce, la controverse portait sur l'opportunité et la légitimité d'utiliser ce procédé législatif.

(40) Cf. par exemple, M. Lobo de Freitas, "Bis in idem", publié le 29 juin 2004 sur le site suivant: AOL. <http://noticias.aol.com.br/negocios/industria/2004/06/0009.adp>; INSTITUTO DANNEMANN SIEMSEN DE ESTUDOS DE PROPRIEDADE INTELECTUAL. Comentários à Lei da Propriedade Industrial, cit., p. 492; D. Barbosa, "A inconstitucionalidade de anuência da ANVISA no procedimento de concessão de patentes como manifestação discricionaria da Administração Federal", julho de 2004. Nous pensons toutefois que ce type de contrôle peut rentrer dans le champ d'application de l'article 8.1 de l'accord sur les ADPIC qui reconnaît explicitement le droit pour les Membres de l'OMC d'adopter des politiques répondant à leurs préoccupations de santé publique.

(41) Loi n. 10.196 publiée au DOU du 16 février 2001. 
Au niveau constitutionnel d'abord, le Brésil présente cette particularité d'avoir inscrit dans sa Constitution de 1988 une disposition atypique qui, rompant avec l'argument de neutralité historique du droit des brevets, soumet ce dernier au développement social, économique et technologique du pays. Quand traditionnellement, la fonction des brevets réside dans la seule récompense de l'innovation ${ }^{(42)}$, l'article 5-XXIII reconnaît la fonction sociale de la propriété(43) et l'article 5-XXIX impose qu'un lien soit établi, d'une manière ou d'une autre, entre l'invention dont la brevetabilité est revendiquée et l'intérêt social, économique et technologique du Brésil(44). Compte tenu du principe de la hiérarchie des normes juridiques, cette préoccupation se retrouve ensuite au sein du droit des brevets, et plus précisément au cœur de l'article 240 de la loi de 1996, celui-là même qui donne compétence à l'INPI pour exécuter sur le plan national les lois qui régissent la propriété industrielle en tenant compte de ses fonctions sociales, économiques, juridiques et techniques ${ }^{(45)}$. Ainsi, en soumettant la brevetabilité des médicaments à l'autorisation préalable de l'ANVISA, l'État reconnaît leur nature particulière, plus précisément, leur importance vitale et sociale. ${ }^{(46)}$ Ce mécanisme reflète bien la volonté du gouvernement brésilien d'œuvrer en faveur de l'accès aux médicaments, volonté illustrée par ailleurs par la mise en œuvre en 1996 du programme d'accès universel et gratuit aux antirétroviraux.

Concrètement, à compter du 14 décembre 1999, les demandes de brevets relatives à des produits ou procédés pharmaceutiques ont été soumises à l'examen de l'INPI, puis à celui de l'ANVISA. L'INPI se charge de l'analyse des critères classiques de brevetabilité (nouveauté, activité inventive et application industrielle) en tant que tels et l'ANVISA examine ces mêmes critères au regard des exigences sanitaires. On peut toutefois regretter l'absence de norme juridique précise relative aux critères d'analyse de l'ANVISA, qui peut engendrer une certaine insécurité juridique: les seules lignes directrices publiées le 12 avril 2005 sur le site de l'ANVISA recommandent à l'Agence de se baser sur les critères de brevetabilité tels que définis dans la loi de propriété industrielle ${ }^{(47)}$. De plus, le caractère de facto aléatoire de l'autorisation de

(42) B. Remiche et H. Desterbecq, préc., p. 11.

(43) Artigo $5^{\circ}-X X I I I:$ "A propriedade atendera a sua função social".

(44) Artigo 5-XXIX: "A lei assegura aos autores de inventos industrias privilégio temporário para sua utilização, bem como proteção às criações industriais, [...], tendo em vista o interesse social e o desenvolvimento tecnologico e econômico do País".

(45) Artigo 240: "O INPI tem por finalidade principal executar, no âmbito nacional, as normas que regulam a propriedade industrial, tendo em vista a sua função social, econômica, jurídica e técnica, bem como pronunciar-se quanto à conveniência de assinatura, ratificação e denúncia de convenções, tratados, convênios e acordos sobre propriedade industrial".

(46) RODRIGUES, E. Beas. Anuência prévia: integração do direito à saúde aos direitos de propriedade intelectual. out. 2005. p. 3.

(47) As linhas diretrizes dispõem, de fato que: "a Anvisa esclarece que todas as análises realizadas pela Anvisa tem por base exclusivamente os requisitos legais previstos nos instrumentos vigentes sobre o tema". 
I'ANVISA peut porter atteinte à la légitimité d'un tel contrôle. Toujours est-il qu'à défaut d'autorisation préalable de l'ANVISA, un brevet dans le domaine pharmaceutique ne peut être délivré(48). L'ANVISA peut donc jouer un rôle primordial, en tant qu'elle peut limiter le champ de la brevetabilité des produits et procédés pharmaceutiques. En effet, elle peut interpréter plus strictement les critères classiques de brevetabilité et pourrait exclure les mee-too drugs $^{(49)}$. les associations de composants connus - à l'instar des trithérapies - et les deuxièmes indications thérapeutiques ${ }^{(50)}$ de la brevetabilité (notons que l'accord sur les ADPIC est silencieux en la matière, ce qui donne toute latitude aux Etats membres pour délivrer ou non des titres de brevets pour ces types d'inventions). En cela, elle participe à l'accès aux médicaments: dans ce cas en effet, les médicaments ne sont pas protégés par des brevets et peuvent être fabriqués localement à des coûts souvent bien inférieurs aux prix du marché.

En pratique, l'ANVISA refuse de donner depuis 2004 son anuência prévia pour des demandes de brevets relatives à une deuxième indication thérapeutique. Dans une note technique du 25 août 2004, ${ }^{(51)}$ l'ANVISA interdit en effet la brevetabilité de telles inventions, aux motifs qu'elles ne remplissent pas le critère de nouveauté d'une part, et qu'elles préjudicient à l'accès aux médicaments d'autre part. L'exclusion des deuxièmes indications thérapeutiques du domaine de la brevetabilité engendre alors la conséquence suivante: un médicament breveté, pour lequel on découvre de nouvelles indications thérapeutiques pendant ou après la période de protection conférée par le brevet, sera "génériquable" dès la chute de son brevet dans le domaine public, les nouvelles indications ne pouvant faire l'objet d'une nouvelle protection. Cet exemple montre bien que I'ANVISA est dotée d'un pouvoir de contrôle sur la brevetabilité des médicaments au Brésil et participe de la promotion de la santé publique.

Ce contrôle que l'on pourrait qualifier de "sanitaire" ne s'exerce toutefois pas sans donner lieu à des différends entre les deux institutions publiques. Dans le cas des deuxièmes indications thérapeutiques en effet, l'INPI avait quant à lui opté pour une position plus souple à travers des lignes directrices ${ }^{(52)}$. Il considérait alors que le Brésil, en tant que pays émergent,

(48) RODRIGUES, E. Beas. op. cit., préc., p. 7.

(49) Un me-too drug est un médicament dont la structure du composé chimique est structurellement très similaire à un médicament déjà connu et qui présente des différences pharmacologiques mineures.

(50) On parle de nouvelle indication thérapeutique, lorsqu'on découvre une nouvelle utilisation pour un produit qui a déjà un usage pharmaceutique connu.

(51) ANVISA. Esclarecimentos sobre pedidos de patentes dos produtos e processos farmacêuticos. Disponível em: <http://www.anvisa.gov.br/divulga/alertas/2004/250804.htm>.

(52) Lignes directrices pour l'examen des demandes de brevet dans les domaines biotechnologiques et pharmaceutiques déposées après le 31 décembre 1994, publiées sur le site suivant: <http:// www.agif.com.br/download/INPI-diretrizes\%20para\%20exame.doc>. 
avait tout intérêt à reconnaître la brevetabilité des deuxièmes indications thérapeutiques, ce type d'invention constituant un marché de niche. Ses guidelines avaient comme objectif le développement industriel du Brésil en tant que pays exportateur de technologie et s'opposaient dès lors à celles de l'ANVISA, qui font primer l'intérêt sanitaire du public sur les intérêts économiques des entreprises. On peut observer que la résolution de tels litiges n'a pas été organisée du point de vue juridique. C'est pourquoi, en pratique, des réunions techniques d'experts ont lieu pour tenter d'harmoniser in concreto les divergences de vues entre ces deux institutions ${ }^{(53)}$. A défaut de consensus, comme indiqué précédemment, la position de l'ANVISA prévaut, car son autorisation préalable est nécessaire à la délivrance du brevet pharmaceutique.

Le contrôle original exercé par l'ANVISA a été légitimé par une décision de justice récente, opposant Aventis Pharma à l'INPI et à l'ANVISA ${ }^{(54)}$. Aventis Pharma contestait la non délivrance d'autorisation préalable et corrélativement la non délivrance de brevet. La 38 s'est fondée sur l'article 5-XXIX de la Constitution de 1988 pour juger que des droits de propriété intellectuelle ne peuvent être délivrés au Brésil, que dans la mesure où ils respectent l'intérêt social, économique et technologique du pays. La décision justifie alors l'intervention de l'ANVISA dans le processus d'analyse des demandes de brevets pour des inventions pharmaceutiques, le raisonnement suivi par la Cour étant le suivant: dans le secteur particulier des médicaments, l'autorisation de l'ANVISA s'avère légitime car elle permet de vérifier que les demandes de brevets répondent aux critères de brevetabilité et aux objectifs de santé publique du pays. A contrario, lorsque les critères de brevetabilité ne sont pas strictement remplis, l'ANVISA peut ne pas donner son autorisation préalable et empêcher la brevetabilité de l'invention revendiquée.

L'ANVISA n'est pas la seule institution publique qui bénéficie d'un pouvoir de contrôle relatif à la délivrance des brevets pharmaceutiques; en effet, le laboratoire public Far-Manguinhos jouit également d'un certain droit de participation au processus d'examen de la demande de brevet.

\section{Le rôle du laboratoire public Far-Manguinhos}

Créé en 1956, Far-Manguinhos constitue le laboratoire officiel du Ministère de la santé. Considéré comme le centre de référence en recherche et développement, technologie et production de médicaments au Brésil, il

(53) Ce qui représente 4 à $5 \%$ des demandes de brevets dans le domaine pharmaceutique, selon les données de l'ANVISA.

(54) Processo n. 2004.51.01.513854-1, de 5 setembro de 2005. 
joue un rôle essentiel dans la problématique de l'accès aux médicaments contre le sida. En effet, il a été le premier laboratoire public à fabriquer des antirétroviraux (ARVs) dits "similaires"(55) pour satisfaire les besoins du programme national de lutte contre le sida. II faut préciser qu'au Brésil, la distribution d'ARVs est gratuite et universelle pour tout porteur du virus ou de la maladie depuis une loi du 13 novembre $1996^{(56)}$ et s'effectue à travers le système brésilien de santé public (SUS) ${ }^{(57)}$; le SUS repose sur un réseau de laboratoires publics, chargés de fabriquer, à la demande du Ministre de la santé, les médicaments essentiels et les ARVs. Encourageant la production endogène de médicaments similaires - copies de médicaments qui ne sont pas brevetés au Brésil ou dont le brevet est tombé dans le domaine public - , cette politique sanitaire présente un double intérêt: premièrement, elle permet de réduire les coûts de prise en charge sanitaire et deuxièmement, elle incite à la R\&D et corrélativement au développement des capacités pharmaceutiques locales ${ }^{(58)}$, à l'instar de Far-Manguinhos.

L'article 31 de la loi de 1996 confère à ce laboratoire un droit de participation au processus d'examen de la demande de brevet; en effet, tout tiers intéressé peut communiquer, à compter de la publication de la demande de brevet et jusqu'à la fin de l'examen de ladite demande, toutes les pièces et informations propres à faciliter l'examen de la demande de brevet ${ }^{(59)}$. Si cette disposition n'est pas en elle-même originale - de nombreux pays prévoient en effet ce type de mesures légales -, son utilisation est quant à elle notable. En effet, son champ d'application revêt un caractère large, puisqu'il suffit de démontrer un intérêt à participer au processus d'examen. II couvre alors non seulement les personnes privées, classiquement intéressées par ce type d'intervention pour défendre leurs intérêts industriels, mais aussi les personnes publiques, dans la mesure où elles ont un intérêt, public cette fois, à défendre.

C'est ce droit de participation que Far-Manguinhos a exercé le 6 décembre 2005 pour contester la demande de brevet du Tenofovir(60) déposée en 1998 par Gilead Sciences, Inc. ${ }^{(61)}$. L'enjeu de cette molécule résidait dans son caractère de traitement de "seconde ligne" ou "de deuxième génération",

(55) Far-Manguinhos ne produit pas de médicaments génériques, mais des médicaments similaires; ces derniers n'étant pas soumis aux tests de bioéquivalence et de biodisponibilité.

(56) Loi n. 9.313.

(57) Sistema único de Saúde.

(58) BERNARDES, Marques M. Saúde pública, ética e mercado no entreato de dois séculos. São Paulo: Brasiliense, 2005. p. 77.

(59) Artigo 31. "Publicado o pedido de patente e até o final do exame, será facultada a apresentação, pelos interessados, de documentos e informações para subsidiarem o exame".

(60) Le Tenofovir est un inhibiteur de la transcriptase inverse, indiqué en association avec d'autres antirétroviraux dans le traitement des malades infectés par le $\mathrm{VIH}-1$ qui ne répondent pas aux autres traitements.

(61) Demande de brevet n. PI9811045-4. 
qui est amené à remplacer les trithérapies originelles du fait de l'accroissement du nombre de patients résistants aux molécules de première ligne et de patients en échec thérapeutique (pour lesquels les trithérapies de première ligne ne fonctionnement pas). Or, un brevet délivré pour ce type de molécule engendre un prix de vente élevé. Alors que la non délivrance d'un brevet permettrait aux génériqueurs brésiliens, Far-Manguinhos plus précisément, de fabriquer des copies moins onéreuses; on comprend donc parfaitement l'intérêt à agir du laboratoire.

Concrètement, Far-Manguinhos a déposé un dossier auprès de l'INPI pour démontrer le défaut d'activité inventive du Tenofovir. L'argumentaire du laboratoire public est le suivant: pour pouvoir être brevetable, une invention doit remplir les trois critères de brevetabilité énoncés à l'article 8 de la loi de 1996: nouveauté, activité inventive, application industrielle. Selon l'article 13 de la loi, l'activité inventive est définie comme étant une activité qui ne découle pas de façon évidente de l'état de la technique ${ }^{(62)}$. L'état de la technique est constitué quant à lui de tout ce qui a été rendu accessible au public, avant la date de dépôt de la demande de brevet, par une description écrite ou orale, par une utilisation ou par tout autre moyen, au Brésil ou à l'extérieur ${ }^{(63)}$. Or, suite à une recherche d'antériorité faite par Far-Manguinhos, il apparaît premièrement que le Tenofovir ne présente qu'une légère modification par rapport à d'autres molécules, connues et brevetées aux États-Unis mais pas au Brésil, et deuxièmement que cette modification découle de façon évidente de l'état de la technique. En effet, la technique d'obtention du Tenofovir ayant été décrite dans des articles scientifiques et dans des demandes de brevets de molécules analogues, tout spécialiste du domaine peut aisément reproduire la technique d'obtention du Tenofovir. On peut se demander quelle sera la position de l'INPI face à ces arguments.

Ainsi, le Brésil a cherché à intégrer les standards internationaux d'une façon qui promeuve malgré tout l'accès à des médicaments pas trop onéreux. Toutefois, il n'a pas été au bout de cette démarche, puisque certaines dispositions s'avèrent insuffisantes au regard des enjeux de santé publique.

\section{LES LACUNES DE LA LÉGISLATION BRÉSILIENNE}

Alors que le Brésil semblait résolu à intégrer les pré-requis internationaux en matière de propriété industrielle d'une manière qui affecte le moins possible l'accès aux médicaments, il n'a pas été au bout de cette démarche.

(62) Artigo 13: "A invenção é dotada de atividade inventiva sempre que, para um técnico no assunto, não decorra de maneira evidente ou óbvia do estado da técnica".

(63) Artigo $11 \S 1$ 10: "O estado da técnica é constituído por tudo aquilo tornado acessível ao público antes da data de depósito do pedido de patente, por descrição escrita ou oral, por uso ou qualquer outro meio, no Brasil ou no exterior, ressalvado o disposto nos arts. 12, 16 e 17". 
En effet, le pays a non seulement fait de la législation internationale une application plus stricte que de rigueur (A), mais il n'a pas achevé de transposer certaines des flexibilités prévues pour développer l'accès aux médicaments parmi les plus importantes (B).

\section{A. Le Brésil au-delà des contraintes internationales}

Alors que le Brésil, de par son statut de pays en développement disposait d'un certain délai pour adapter sa législation en matière de propriété industrielle; or, il a choisi de se conformer dès 1996 aux prescriptions de l'accord sur les ADPIC (1). En outre, il a instauré un système de protection des "pipelines de brevets", système non prévu par la législation internationale (2).

\section{Une application précoce de la législation internationale}

L'accord sur les ADPIC a prévu des dispositions transitoires relatives à sa mise en œuvre, de façon à tenir compte des différents niveaux de développement des Etats membres ${ }^{(64)}$ : les pays développés disposaient d'un an pour se mettre en conformité avec les dispositions contenues dans l'accord, les pays en développement bénéficiaient d'un délai de cinq ans et les pays les moins avancés d'un délai de dix ans. En outre, des dispositions transitoires spéciales s'appliquent dans le cas où un pays en développement ne prévoit pas la protection par des brevets de produits des produits pharmaceutiques. Dans cette hypothèse, le membre dispose d'une période additionnelle de cinq ans pour organiser ladite protection ${ }^{(65)}$. Ainsi le Brésil, l'Inde, etc. ... avaient jusqu'au 1er janvier 2005 pour modifier leur législation en matière de brevets pharmaceutiques. Ils pouvaient alors jouir de ce délai pour développer leurs industries génériques et produire des copies de médicaments brevetés à bas prix. Mais si l'Inde a pleinement profité de cette période transitoire ${ }^{(66)}$, le Brésil a reconnu la brevetabilité des produits pharmaceutiques dès 1996. Ainsi, à compter du 14 mai 1997, date d'entrée en vigueur de la loi, le Brésil devait délivrer et respecter les brevets dans le secteur pharmaceutique.

Cette stratégie surprenante s'explique par les pressions exercées par le gouvernement américain dès 1987 sous couvert de la Section 301 du

(64) Articles 65 et 66 de l'accord sur les ADPIC.

(65) Article 65-4 de l'accord dispose en effet: "dans la mesure où un pays en développement Membre a l'obligation, en vertu du présent accord, d'étendre la protection par des brevets de produits à des domaines de la technologie qui ne peuvent faire l'objet d'une telle protection sur son territoire à la date d'application générale du présent accord pour ce Membre [...], ledit Membre pourra différer l'application des dispositions en matière de brevets de produits [...] à ces domaines de la technologie pendant une période additionnelle de cinq ans".

(66) L'Inde a en effet modifié sa législation en matière de propriété industrielle le 25 mars 2005. 
Trade and Tariff Act (1984)(67). Le 11 juin 1987, la $P h R M A^{(68)}$ - association qui regroupe les principales industries pharmaceutiques américaines - avait en effet envoyé une pétition au gouvernement américain, estimant que le Brésil avait adopté une pratique déraisonnable du fait du défaut de reconnaissance des brevets pharmaceutiques. ${ }^{(69)}$ Le représentant américain au commerce (USTR) classa alors le Brésil dans la catégorie de "pays étrangers prioritaires " et commença ses investigations. Le Président brésilien Sarney, souhaitant trouver un compromis pour stopper le conflit, annonça une réforme législative sur la brevetabilité des produits pharmaceutiques en juin 1988. Cette réforme jugée insatisfaisante par le Président Reagan, les Etats-Unis appliquèrent des mesures de rétorsions commerciales (un tarif de $100 \%$ ad valorem) sur certains types de papiers, de produits chimiques et d'articles électroniques brésiliens.

C'est l'élection du Président néo-libéral Collor et sa proposition en juin 1990 de réforme de la législation brésilienne en matière de propriété industrielle qui désamorcèrent le conflit et firent cesser les sanctions commerciales américaines. Mais le rejet du projet de loi Collor, en avril 1993, par la chambre des députés en raison de divergences d'opinions sur l'étendue de la brevetabilité et les droits du titulaire du brevet ${ }^{(70)}$ déclencha de nouveau les foudres du gouvernement américain. L'ultimatum était le suivant: ou le Brésil reconnaissait la brevetabilité des produits pharmaceutiques avant le mois de février 1994, ou de nouvelles investigations et sanctions commerciales seraient appliquées à son encontre. Les négociations brésiliennes aboutirent à l'adoption de la loi de 1996, compromis entre le Brésil et les Etats-Unis, et plus précisément entre les intérêts nationaux et les exigences des entreprises multinationales. Et l'évocation de ce vieux conflit explique donc pourquoi le Brésil n'a pas profité des dispositions transitoires spéciales. En effet, même si l'ambassadeur Rubens Barbosa affirmait que le Brésil n'allait pas modifier sa législation du fait de pressions américaines ${ }^{(71)}$, il semble difficile d'imaginer - dans un tel contexte - que le Brésil repousse l'adoption de sa réforme législative!

Ainsi, le Brésil n'a pas profité de la période de transition qui lui était offerte pour mettre sa législation en conformité avec la législation internatio-

(67) BARBOSA, D. Uma introdução à propriedade intelectual. 2. ed. Rio de Janeiro: Lúmen Juris, 2003. p. 7.

(68) Pharmaceutical Research and Manufacturers of America.

(69) La raison du conflit tenait au fait que le Brésil représentait un marché très important pour les investisseurs américains (7ème place au classement mondial). Cf. TACHINARDI, M. A guerra das patentes: o conflito Brasil \& EUA sobre Propriedade Intelectual. Rio de Janeiro: Paz e Terra, 1993. p. 112. (70) Les points de divergence portaient alors sur la brevetabilité ou non des êtres vivants (microorganismes, plantes et animaux) et des médicaments essentiels, sur la protection des pipelines de brevets, sur la durée de la protection offerte par le brevet, sur les motifs de délivrance des licences obligatoires et sur les importations parallèles.

(71) TACHINARDI, M. op. cit., préc., p. 31. 
nale. II a en outre adopté une série de mesures - non préconisées par l'accord sur les ADPIC — de façon à protéger les "pipelines de brevets".

\section{Des mesures de protection des pipelines ${ }^{(72)}$ de brevets}

L'accord sur les ADPIC ne prévoit pas de mesures relatives aux pipelines de brevets, bien que les États-Unis aient revendiqué ce type de protection tout au long du cycle d'Uruguay ${ }^{(73)}$. La protection des pipelines de brevets consiste en fait en une forme de protection rétroactive des médicaments déjà brevetés dans d'autres pays, mais qui n'ont pas encore été brevetés dans le pays objet du pipeline (parce que la législation du pays en question ne reconnaissait pas la brevetabilité des inventions pharmaceutiques), ni commercialisés dans ce pays ${ }^{(74)}$. Au vu de la préoccupation américaine constante eu égard à la protection des brevets en général, et des brevets pharmaceutiques en particulier, et au vu des pressions exercées par le gouvernement américain, telles que décrites précédemment, on pourrait très bien imaginer que le Brésil ait été poussé à organiser la protection des pipelines de brevets.

Concrètement, la législation brésilienne de 1996 a organisé un mécanisme temporaire de protection des pipelines de brevets dans le titre VIII relatif aux dispositions transitoires et finales ${ }^{(75)}$. En vertu de ce mécanisme, un brevet peut être délivré au Brésil pour une invention relative à des produits ou procédés pharmaceutiques ${ }^{(76)}$. lorsqu'il a déjà été délivré dans le pays de la première demande, à condition que l'objet du brevet n'ait pas été commercialisé au Brésil par le titulaire du brevet ou par des tiers avec son consentement. En d'autres termes, des brevets peuvent être délivrés au Brésil pour des inventions qui ont déjà été divulguées et qui ne répondent de facto plus au critère de nouveauté. Notons que ces brevets sont délivrés de façon automatique, sans examen technique ( $i$. e. sans rechercher si les critères de

(72) Les pipelines de brevets sont les portefeuilles de molécules brevetées, qui n'ont pas encore été commercialisées, dont les laboratoires pharmaceutiques disposent.

(73) MONDIALISATION et accès aux médicaments: perspectives sur l'accord ADPIC de l'OMC. Programme d'Action pour les Médicaments Essentiels, 1999. p. 51. (Série Economie de la Santé et Médicaments, n. 7.

(74) Attention à ne pas confondre ce mécanisme avec le système de "boîte aux lettres" prévu par l'article 70.8 de l'accord sur les ADPIC pour les pays qui ne reconnaissaient pas la brevetabilité des inventions pharmaceutiques au 1er janvier 1995, indépendamment de la période de transition qui leur était accordée. Ces derniers devaient mettre en place à compter de cette date, une infrastructure adéquate pour recevoir les demandes de brevets de produits pharmaceutiques. Cet artifice juridique permettait de préserver la nouveauté des inventions découvertes à partir de 1995 mais qui ne pouvaient pas recevoir de protection par brevet avant une dizaine d'années au maximum. Si la demande remplissait bien les trois critères de brevetabilité, qui étaient évalués à la date du dépôt, le brevet était délivré pour une période de vingt ans, cette période commençant à courir à la date du dépôt de la demande.

(75) Articles 229, 230 et 231 de la loi de 1996.

(76) En réalité, le mécanisme s'applique aussi aux produits et procédés chimiques et alimentaires. 
brevetabilité sont réunis, à savoir nouveauté, activité inventive, application industrielle), à partir du moment où ils ont été délivrés à l'étranger. Les brevets ainsi délivrés au Brésil correspondent aux brevets délivrés originellement. La protection pipeline représente donc une exception au concept classique de brevetabilité, puisqu'elle fonctionne comme une "revalidation" des brevets acquis à l'étranger ${ }^{(77)}$. Ce mécanisme juridique s'applique aux pipelines de brevets étrangers et aux pipelines de brevets nationaux (dans ce dernier cas toutefois, la date de départ de la protection court à compter de la date de première divulgation de l'invention et les demandes sont instruites conformément aux critères classiques de brevetabilité, le critère de nouveauté étant néanmoins examiné avec souplesse).

Cette protection connaît toutefois des limites. Tout d'abord, le brevet délivré en vertu de cette protection est délivré pour une durée équivalente à celle qui reste à courir dans le pays de la première demande ${ }^{(78)}$. Ensuite, la protection pipeline ne vaut que pour les demandes présentées entre la date de promulgation et la date d'entrée en vigueur de la loj ${ }^{(79)}$.

Enfin, notons que ce mécanisme juridique a fait l'objet de vives controverses parmi les institutions scientifiques brésiliennes, la société civile et les entreprises nationales ${ }^{(80)}$, du fait qu'il prévoit une protection supérieure

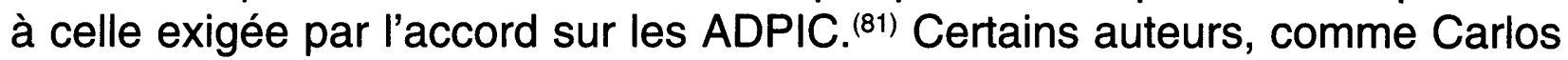
Correa, ont même été jusqu'à dénoncer l'inconstitutionnalité du mécanisme, en invoquant son incompatibilité avec le critère de nouveauté: "thus, the US government and the pharmaceutical industry have attempted to obtain a retroactive recognition of protection for pharmaceuticals that are already patented (the so-called "pipeline" protection). The Andean Court of Justice (established by the Cartagena Agreement) declared in a decision (Process $n$. 1-Al-96) on 30 October 1996, that the «pipeline" formula was inherent contradictory with the novalty requirement under patent law, and thus rejected the retroactive registration of patents in the subregion."(82)

(77) INSTITUTO DANNEMANN SIEMSEN DE ESTUDOS DE PROPRIEDADE INTELECTUAL. Comentários à Lei da Propriedade Industrial, cit., p. 493.

(78) Article 230-4 de la loi de 1996.

(79) Article 230-1 de la loi de 1996.

(80) Disse José Serra, Ministro da Saúde: "A incorporação do mecanismo do pipeline à lei de patentes foi uma concessão desnecessária feita pelo Brasil, dado que não era uma exigência do Acordo TRIPS, sendo alvo de críticas até hoje." CORREA, Carlos. El Acuerdo TRIPs. Buenos Aires: Ed. Ciudad Argentina, 1996, confirma tal declaração: "el Acuerdo adopto una posición a dicho reconocimiento, rechazando soluciones tipo "pipeline". Los articulos 70.1 y 70.3 disponen al respecto que el Acuerdo no genera obligaciones relativas a actos realizados antes de la fecha de aplicación del Acuerdo para Miembro (art. 70.1) y no obliga a restabelecer la protección de la materia que en esa fecha haya pasado al dominio publico (art. 70.3)."

(81) BERMUDEZ, J.; EPSTEJN, R.; OLIVEIRA, M.; HASENCLEVER, L. The WTO TRIPS Agreement and Patent Protection in Brazil: recent changes and implications for local production and access to Medicines. Rio de Janeiro: WHO/PAHO/ENSP, Apr. 2000. p. 70.

(82) BARBOSA, D. op. cit., p. 639. 
Ainsi, le Brésil a fait une application a maxima de la législation internationale à travers son adaptation immédiate aux standards internationaux et l'instauration de la protection "pipeline". II n'a pas non plus transposé tous les mécanismes favorisant l'accès aux médicaments.

\section{B. Une transposition inachevée des mécanismes favorisant l'accès aux médicaments}

Outre le mécanisme de licence obligatoire, l'accord sur les ADPIC permet une autre flexibilité classique destinée à faciliter l'accès aux médicaments: les importations parallèles. La décision du 30 août 2003 a poussé cette flexibilité beaucoup plus loin et organisé un mécanisme juridique original favorisant la fourniture de médicaments génériques aux pays les plus pauvres et indirectement, le développement de l'industrie du générique. Or, le Brésil n'a pas profité pleinement des flexibilités ainsi offertes par la législation internationale. En effet, il n'a pas suffisamment exploité le mécanisme des importations parallèles (1); il n'a pas non plus transposé la décision d'août 2003 perdant ainsi une opportunité (2).

\section{Des importations parallèles sévèrement limitées}

Une autre flexibilité est offerte par l'accord sur les ADPIC pour limiter les effets du monopole du titulaire d'un brevet, celle qui concerne la question des importations parallèles. Cette flexibilité résulte de la doctrine allemande de l'épuisement du droit du breveté fondée par Kohler et de la décision du Reisgericht du 26 mars 1902 qui énonce : «le brevet concernant un procédé a pour effet que personne, hors le titulaire [et les personnes qu'il aurait autorisées] ne peut fabriquer le produit selon ce procédé et le mettre en circulation à l'intérieur du pays. Par cet acte, toutefois, l'effet de la protection conférée par le brevet s'épuise. Le titulaire qui a fabriqué le produit et l'a mis en circulation sous cette protection qui exclut la concurrence d'autres personnes a joui des avantages que le brevet lui confère et a ainsi consommé son droit. Le brevet n'accorde pas à son titulaire le pouvoir de soumettre la circulation du produit à des conditions déterminées."(83) Ainsi, en vertu de cette construction juridique, l'inventeur est récompensé de son effort créatif au moment où il commercialise pour la première fois son invention. A compter de cette première commercialisation (par lui ou par ses ayants droits), ses droits sont dits "épuisés": il ne peut dès lors plus se baser sur son brevet pour interdire la libre circulation de son invention et a fortiori pour empêcher les importations parallèles de son invention. Cette vision limitée du droit de brevet prend une importance considérable dans le commerce international.

(83) Cf. FOYER, J.; VIVANT, M. Le droit des brevets. Paris: Thémis, 1990. p. 327. 
En pratique en effet, les importations parallèles résultent des stratégies d'entreprises de fixation des prix en fonction des différents marchés. Dans le domaine pharmaceutique, elles consistent en ce "qu'un importateur fait entrer sur le territoire d'un État $A$ où le prix d'un médicament est élevé, le même médicament préparé ou acheté dans un autre État $B$ où le prix est moins élevé, bénéficiant ainsi du différentiel de prix existant". ${ }^{(84)}$ Elles permettent ainsi à des grossistes importateurs - en profitant des stratégies commerciales des laboratoires pharmaceutiques - d'importer des médicaments à des prix moins chers. Ainsi, les importations parallèles permettent-elles aux consommateurs d'obtenir le meilleur prix sur le marché mondial pour un médicament breveté. ${ }^{(85)}$ Ce faisant, elles peuvent empêcher les titulaires de brevets de segmenter les marchés et limiter les discriminations en matière de prix à l'échelon régional ou international. Et c'est en cela qu'elles peuvent contribuer à l'accès aux médicaments. On comprend donc parfaitement pourquoi les pays en développement ont intérêt à mettre en œuvre ce mécanisme et à rechercher partout dans le monde des médicaments moins chers.

L'accord sur les ADPIC, s'il réglemente avec une relative précision les licences obligatoires, fait une référence très ponctuelle à l'épuisement des droits à l'article 6, lequel indique que la question de l'épuisement des droits de propriété intellectuelle ne peut être réglée par le Mémorandum d'accord sur le règlement des différends, à moins d'un recours sur la base d'une discrimination ${ }^{(86)}$. Concrètement, cela signifie que les États membres peuvent choisir le régime de leur choix concernant l'épuisement des droits. L'accord n'imposant en effet aucune obligation en la matière, cette question reste de compétence purement nationale. Les États membres ont donc toute latitude pour appliquer:

— un épuisement international ou la possibilité pour un tiers d'importer sur le territoire de l'Etat membre concerné le même produit breveté en provenance de n'importe quel autre Etat où il aurait été commercialisé avec le consentement du titulaire du brevet ou de ses ayants droits ; ce type d'épuisement présente l'avantage de rechercher les meilleurs prix pour les consommateurs, au détriment toutefois du développement de l'industrie locale;

— un épuisement régional à l'instar de l'Union européenne ${ }^{(87)}$ ou la possibilité d'importer sur le territoire d'un État membre le même produit

(84) Définition donnée par VIALA, G.; BURTIN, J.-F. La libre circulation des médicaments et ses limites, au travers de la jurisprudence de la Cour de justice des Communautés européennes. $R D$ San. Soc. V. 34, n. 1, p. 81, janv./mars 1998.

(85) CORREA, Carlos. Intégration des considérations de santé publique dans la législation en matière de brevets dans les pays en développement. South Centre, nov. 2001. p. 82.

(86) Article 6: "aux fins du règlement des différends dans le cadre du présent accord, sous réserve des dispositions des articles 3 et 4, aucune disposition du présent accord ne sera utilisée pour traiter la question de l'épuisement des droits de propriété intellectuelle". 
breveté en provenance de n'importe quel autre État membre de la même union régionale; ou

- un épuisement national qui revient à limiter le droit de circulation des produits couverts par un brevet dans l'État dans lequel s'applique l'épuisement national. Plus simplement, ce type d'épuisement interdit tout simplement les importations parallèles.

Le droit brésilien ne profite pas de la flexibilité offerte par l'accord sur les ADPIC, puisqu'il n'admet qu'un épuisement national des droits du breveté, ${ }^{(88)}$ interdisant de facto les importations parallèles. ${ }^{\left({ }^{(89)}\right.}$. Ce cas de figure représente alors la solution la moins favorable pour les consommateurs, puisque les droits du breveté lui permettent de contrôler totalement la commercialisation du produit. Une fois encore, la solution adoptée par le Brésil apparaît paradoxale au vu de ses préoccupations de santé publique.

Ce principe d'épuisement national doit toutefois être tempéré, des exceptions ayant été prévues. Ainsi, les importations parallèles de produits ou procédés brevetés sont autorisées pour permettre l'exploitation de l'invention, en cas de licence obligatoire pour défaut d'exploitation de l'invention sur le territoire national, ${ }^{(90)}$ et en cas de licence obligatoire pour abus de pouvoir économique. ${ }^{(91)}$ Et depuis un décret de $2003,{ }^{(92)}$ les importations parallèles sont permises en cas de défaillance de la production nationale dans les cas de licences obligatoires en cas d'urgence nationale ou d'intérêt public. ${ }^{(93)}$ Les importations parallèles étant autorisées dans la mesure où le titulaire du brevet a consenti à la première mise sur le marché de son invention. Notons cependant qu'aucune de ces exceptions n'a été mise en œuvre jusqu'à présent.

Outre le fait que le Brésil n'a pas utilisé pleinement le mécanisme des importations parallèles, il n'a pas par ailleurs transposé la décision originale du 30 août 2003 relative à la fourniture de médicaments génériques dans les pays les plus pauvres.

(87) La Cour de justice des Communautés européennes a, pour promouvoir la libre circulation des marchandises sur le territoire communautaire, consacré le principe de l'épuisement communautaires des droits du brevet dans l'arrêt Centrafarm c/ Sterling Drug du 31 octobre 1974 (aff. 15/74: Rec. CJCE 1974, p. 1147).

(88) L'article 42 dispose: "a patente confere a seu titular o direito de impedir terceiro, sem o seu consentimento, de produzir, usar, colocar à venda, vender ou importar com estes propósitos ".

(89) Les importations parallèles ne sont toutefois pas réprimées pénalement; aussi le tiers qui commet ce type d'infraction aux droits du breveté s'exposera seulement à des sanctions civiles (cf. article 184 II de la loi de 1996).

(90) Cf. article 68-4 de la loi de 1996.

(91) Cf. article 63-3 de la loi de 1996.

(92) Décret n. 4.830 du 4 septembre 2003, publié au DOU du 5 septembre 2003.

(93) Cf. articles 71 de la loi de 1996 et 10 du décret de 2003. 


\section{La non transposition de la décision originale du $\mathbf{3 0}$ août $\mathbf{2 0 0 3}$}

La décision du 30 août 2003 institue des dérogations à deux obligations essentielles énoncées aux paragraphes $f$ et $h$ de l'accord sur les ADPIC, selon lesquelles une licence obligatoire sera autorisée "principalement pour l'approvisionnement du marché intérieur du Membre qui a autorisé cette utilisation" et le titulaire du droit de brevet recevra "une rémunération adéquate selon le cas d'espèce, compte tenu de la valeur économique de l'autorisation". Elle crée donc un véritable statut différencié pour les produits pharmaceutiques, à savoir tout produit pharmaceutique breveté ou tout produit fabriqué au moyen d'un procédé breveté, les principes actifs nécessaires à la fabrication du produit et les kits de diagnostics nécessaires à son utilisation, dans la mesure où ils sont nécessaires pour remédier aux problèmes de santé publique ${ }^{(94)}$.

Concrètement, elle instaure un système de licences obligatoires croisées pour permettre aux pays pauvres, qui ne sont pas en mesure de fabriquer eux-mêmes des médicaments, d'importer plus facilement des médicaments génériques meilleur marché. Car "pour être efficace, une licence obligatoire doit être octroyée à des industriels capables de mettre rapidement sur pied une fabrication aux coûts les plus bas possibles; or de telles capacités de production n'existent pas dans la plupart des pays pauvres, seuls les pays émergents pouvant en disposer"(95).

Ainsi, deux catégories juridiques nouvelles sont créées pour mettre en œuvre ce système: celle de "Membre importateur admissible" qui regroupe les pays les moins avancés et tout autre Membre de l'OMC qui a notifié au Conseil des ADPIC son intention d'utiliser le système en tant qu'importateur(96) (l'Allemagne, l'Australie, l'Autriche, la Belgique, le Canada, le Danemark, l'Espagne, Les États-Unis, la Finlande, la France, la Grèce, l'Irlande, I'Islande, l'Italie, le Japon, le Luxembourg, la Norvège, la Nouvelle Zélande, les Pays Bas, le Portugal, le Royaume Uni, la Suède et la Suisse qui ont indiqué qu'ils n'utiliseraient pas le système en tant que Membre importateur) et celle de "Membre exportateur" qui s'entend d'un Membre utilisant le système pour produire et exporter des produits pharmaceutiques à l'intention d'un Membre importateur admissible ${ }^{(97)}$.

Le système fonctionne de la manière suivante: un Membre importateur déclaré admissible présente au Conseil des ADPIC une notification qui spécifie le nom et la quantité attendue du produit nécessaire pour résoudre son

(94) Cf. le paragraphe 1.a) de la décision.

(95) HERMITTE M.-A. Bioéthique et brevets dans le droit du commerce international: la construction d'un nouveau contrat social. In: MALJEAN-DUBOIS, S. (Dir.) La communauté internationale et les enjeux bioéthiques. Paris: Pedone, 2005.

(96) Paragraphe 1.b) de la Décision.

(97) Paragraphe 1.c) de la Décision. 
problème de santé publique. Il démontre, le cas échéant, qu'il a des capacités de fabrication inexistantes ou insuffisantes dans le secteur pharmaceutique en question ${ }^{(98)}$, et indique qu'il a accordé une licence obligatoire d'importation pour le produit en cause. C'est ensuite au tour du Membre exportateur - qui a été sollicité par le Membre importateur - de notifier au Conseil des ADPIC la délivrance d'une licence obligatoire d'exportation. Cette notification comprend les renseignements suivants: l'identification du titulaire de la licence et du produit à fournir, la quantité, le pays auquel le produit doit être fourni, la durée de la licence et l'adresse du site internet sur lequel les caractéristiques de la licence (quantité, destination et caractéristiques du produit) seront affichées. Notons que ladite licence est soumise à des conditions spécifiques: le volume de produit fabriqué doit correspondre strictement aux besoins du Membre importateur, l'intégralité de la production doit être exportée vers ce dernier et le produit doit être clairement identifié comme étant produit dans le cadre de ce système au moyen d'un étiquetage ou d'un marquage spécifique. Le Membre exportateur peut alors fabriquer et exporter le produit requis vers le Membre importateur. En contrepartie, une rémunération "adéquate" sera versée au titulaire du brevet dans le Membre exportateur, compte tenu "de la valeur économique que représente pour le Membre importateur l'utilisation qui a été autorisée dans le Membre exportateur". ${ }^{(99)}$

Pour éviter le détournement et la réexportation des produits qui ont été importés sur son territoire, le Membre importateur devra prendre des mesures raisonnables, proportionnées à ses capacités administratives et au risque de détournement des échanges, "dans la limite de ses moyens".

Notons que, pour des raisons d'économies d'échelle, dans l'hypothèse où le Membre importateur est partie à un accord commercial régional, ce système pourra être utilisé pour approvisionner les marchés des autres pays en développement ou pays moins avancés qui sont parties audit accord, lorsqu'ils partagent le même problème de santé publique ${ }^{(100)}$.

Une déclaration distincte du Président du Conseil général, ${ }^{(101)}$ destinée à rassurer ceux qui craignaient que la décision puisse être utilisée de manière abusive et compromettre la protection conférée par les brevets, accompagne la décision. Elle précise alors que le système établi devra être utilisé de "bonne foi pour la protection de la santé publique" et ne devra pas être un instrument visant la réalisation d'objectifs de politique industrielle ou commerciale; il reste que, si le Membre exportateur retenu est un pays émergent, cela peut participer au développement de son industrie pharmaceutique par

(98) Les pays les moins avancés sont qualifiés d'office de "Membres importateurs admissibles".

(99) Paragraphe 3 de la Décision.

(100) Paragraphe 6.i) de la Décision.

(101) Déclaration du Président du Conseil général du 30 août 2003 publiée sur le site: <http:// www.wto.org/french/news_f/news03_f/trips_stat_28aug03_f.htm>. 
voie de conséquence. Et elle insiste par ailleurs sur la nécessité de prévenir le détournement des produits, allant jusqu'à fournir des lignes directrices relatives aux "meilleures pratiques". Enfin, elle appelle les Membres de l'OMC à régler avec diligence et à l'amiable toute question découlant de l'utilisation et de la mise en œuvre de la décision.

Alors que le Brésil semble soucieux d'intégrer des considérations d'ordre sanitaire au cœur même de sa législation en matière de propriété industrielle, il n'a pas entamé - à l'heure actuelle - le processus de transposition de la décision sur la mise en œuvre du paragraphe 6 de la Déclaration de Doha. Or, à défaut de réforme du droit interne de façon à intégrer le système proposé par l'Organisation Mondiale du Commerce, le Brésil ne pourra pas en bénéficier. Cet immobilisme juridique peut paraître regrettable pour ce pays - roi des inégalités sociales à plusieurs titres.

Tout d'abord, on peut envisager l'hypothèse selon laquelle le Brésil pourrait avoir recours au système en tant que Membre importateur admissible. Admettons par exemple, qu'il ne dispose pas de capacités de fabrication suffisantes pour produire des antirétroviraux de dernière génération - ceux là mêmes qui constituent l'unique solution thérapeutique dans le cadre d'une montée des résistances aux trithérapies classiques - en cas de flambée épidémique de VIH/SIDA. On pourrait alors très bien concevoir cette hypothèse comme étant un cas d'urgence sanitaire. Or, à défaut de transposition de la décision de 2003 en droit interne, et de notification d'utilisation du système en tant que Membre importateur admissible au Conseil des ADPIC, il ne pourrait pas tirer parti du système pour s'approvisionner - après avoir établi que ses capacités de production dans le secteur pharmaceutique en question étaient insuffisantes - , auprès d'un fournisseur indien par exemple. Cette hypothèse semble d'autant plus plausible que le Brésil n'est pas producteur de principes actifs ${ }^{(102)}$. Il apparaît donc surprenant que le Brésil se prive volontairement d'un nouvel instrument juridique qui participe de l'accès aux médicaments.

On pourrait ensuite très bien imaginer qu'il soit fait appel au Brésil en sa qualité de Membre exportateur. En effet, au vu du succès de son programme de lutte contre le SIDA, le Brésil fait figure d'exemple au niveau international pour avoir ralenti considérablement l'épidémie de SIDA. De plus, le Brésil est connu pour disposer d'une capacité de production à travers son puissant réseau de laboratoires publics (Far-Manguinhos, FUNED, LAFEPE ...) et privés. Même s'il ne faut pas oublier que les laboratoires publics n'ont

(102) Cf. BERMUDEZ, J.; EPSTEJN, R.; OLIVEIRA, M.; HASENCLEVER, L. op. cit., p. 88. CORIAT, B.; DUMOULIN, J.; FLORY, Y.-A.; BARNETT, T.; SOUTEYRAND, Y.; MOATTI, J.-P. Patents, generic drugs and the markets for antiretrovirals. In: MOATTI, J.-P.; CORIAT, B.; SOUTEYRAND, Y. BARNETT, T.; DUMOULIN, J.; FLORY, Y.-A. Economics of AIDS and access to HIVIAIDS care in developing countries. Issues and challenges. ANRS, 2003. p. 32. (Collection Sciences Sociales et SIDA). 
pas le droit d'exporter leur production(103). à l'exception toutefois de Far-Manguinhos $^{(104)}$, ce système pourrait très bien favoriser le développement de l'industrie privée du générique, encore peu développée. Et ce d'autant que le Brésil cherche à conquérir les marchés africains lusophones.

On comprend donc mal pourquoi le Brésil n'envisage pas la transposition de ce nouvel instrument juridique au service de l'accès aux médicaments, alors même qu'il a tiré parti des flexibilités classiques offertes par le droit des brevets pour intégrer des considérations sanitaires au sein du droit du commerce international. On peut en fait envisager plusieurs raisons qui expliqueraient le paradoxe brésilien.

D'abord, il ne faut pas sous-estimer les pressions qu'exercent les ÉtatsUnis sur le Brésil, qui n'est-il pas toujours en mesure d'agir à sa convenance. Rappelons en effet, comme nous le verrons ultérieurement, que le Brésil, soumis à des mesures de rétorsion commerciale américaines, n'a pas eu d'autre choix que de reconnaître de façon précoce la brevetabilité des produits pharmaceutiques. Par ailleurs, il n'est peut être pas inutile de rappeler que même si les États-Unis avaient retiré la plainte qu'ils avaient déposée contre le Brésil devant l'Organe de Règlement des Différends (ORD) de l'OMC en 2001 au motif que certaines dispositions de la loi brésilienne de propriété industrielle de 1996, relatives aux licences obligatoires, étaient incompatibles avec l'accord sur les ADPIC(105), le Brésil avait accepté "au cas où il jugerait nécessaire d'appliquer l'article 68 afin de délivrer une licence obligatoire pour des brevets détenus par des sociétés américaines, d'avoir avec le gouvernement des États-Unis des entretiens préalables sur la question"(106). On pourrait donc très bien imaginer que le défaut de transposition du système offert par la décision du 30 août ait fait l'objet de négociations avec les ÉtatsUnis et participe d'une stratégie globale de négociations commerciales.

Ensuite, au vu des entretiens réalisés dans le cadre de ce travail au sein de l'industrie du générique, on a pu constater un manque d'information

(103) De par leur caractère public en effet, les laboratoires officiels produisent les médicaments requis pour le programme national de lutte contre le SIDA, à la demande du Ministre de la santé. Les laboratoires n'ayant pas vocation à développer leur activité de production au delà des commandes passées par le gouvernement, les excès de production sont donc extrêmement rares.

(104) Far-Manguinhos a en effet été autorisé par la loi n. 10.858 du 13 avril 2004 à exporter les surplus de production éventuels vers des pays avec lesquels le Brésil a signé des accords de coopération.

(105) Les États-Unis contestaient alors la validité de l'article 68 de la loi brésilienne qui prévoit qu'un brevet fera l'objet d'une licence obligatoire si l'objet du brevet n'est pas "exploité" sur le territoire du Brésil, le défaut d'exploitation étant défini par le Brésil, comme étant la non fabrication ou la fabrication incomplète du produit ou l'utilisation incomplète du procédé breveté. Ils estimaient qu'une telle prescription était incompatible avec les obligations découlant pour le Brésil des articles 27 (objet brevetable) et 28 (droits conférés par un brevet) de l'accord sur les ADPIC et de l'article III (principe du traitement national) du GATT de 1994.

(106) Cf. le document WT/DS199/4 du 19 juillet 2001 sur le site de l'OMC. 
du secteur pharmaceutique. En effet, nombre d'industriels n'avaient pas connaissance de l'existence de la décision du 30 août, et partant des possibilités de développement qu'elle leur offre. On ne peut donc qu'encourager les génériqueurs brésiliens à se regrouper pour prendre connaissance des possibilités juridiques offertes par le droit international des brevets pour promouvoir l'accès aux médicaments dans les pays pauvres; et à amener le gouvernement à considérer l'opportunité industrielle offerte par ce mécanisme.

\section{CONCLUSION}

Le Brésil, tout en adaptant sa législation en matière de propriété industrielle aux obligations internationales énoncées par l'accord sur les ADPIC, souhaitait concilier accès aux médicaments et brevetabilité des produits pharmaceutiques. II a, en fait, adopté des stratégies paradoxales: il a exploité au maximum les flexibilités traditionnelles offertes par le droit des brevets; allant plus loin, il a créé des mécanismes juridiques novateurs, à l'image de l'Anuência prévia, pour restreindre le champ de la brevetabilité dans le domaine pharmaceutique. D'un autre côté, il n'a pas profité des flexibilités originales mises à la disposition des États membres par l'accord sur les ADPIC, dépassant même parfois les exigences requises par le droit du commerce international. 